\title{
Social Learning Theory
}

\author{
ALBERT BANDURA \\ Stanford University
}

(C) 1971 General Learning Corporation

All rights reserved. No part of this publication may be reproduced or transmitted in any form or by any means, electronic or mechanical, including photocopy, xerography, recording, or any information storage and retrieval system without permission in uriting from the publisher.

Manufactured in the United States of America

Library of Congress Catalog Card Number 75-1 70398

4023000

\begin{abstract}
M vew, popularized by various personality doctrines, depicted behavior as impelled by inner forces in the form of needs, drives, and impulses, often operating below the level of consciousness. Since the principal causes of behavior resided in forces within the individual, that is where one looked for explanations of man's actions. Although this view enjoyed widespread professional and popular acceptance, it did not go unchallenged.

Theories of this sort were criticized on both conceptual and empirical grounds. The inner determinants were typically inferred from the behavior they supposedly caused, resulting in pseudo explanations. Thus, for example, a hostile impulsc was deduced from a person's irascible behavior, which was then attributed to the action of the underlying impulse. Different personality theories proposed diverse lists of motivators, some containing a few all-purpose drives, others embracing a varied assortment of specific drives.

The conceptual structure of psychodynamic theories was further criticized for disregarding the tremendous complexity of human responsiveness. An internal motivator cannot possibly account for the marked variation in the incidence and strength of a given behavior in different situations, toward different persons, at different times, and in different social roles. When diverse social intluences produce correspondingly diverse behaviors, the inner cause implicated in the relationship cannot be less complex than its effects.

While the conceptual adequacy of psychodynamic formulations was debatable, their empirical limitations could not be ignored indefinitely. They provided intriguing interpretations of events that had already happened, but they lacked power to predict how people
\end{abstract}




\section{Albert Bandura}

would behave in given situations [Mischel 1968] Moreover, it was difficult to demonstrate that persons who had undergone psychodynamically oriented treatment benefited more than nontreated cases [Bandura 1969a, Bergin 1966]. Acquiring insight into the underlying impulses through which behavioral changes were supposedly achieved tumed out to represent more of a social conversion than a selfdiscovery process. As Marmor [1962], among others, pointed out, each psychodynamic approach had its own favored set of inner causes and its own preferred brand of insight. The presence of these determinants could be easily confirmed through suggestive probing and selective reinforcement of clients' verbal reports in self-validating interviews. For these reasons, advocates of differing theoretical orientations repeatedly discovered their favorite psychodynamic agents but rarely found evidence for the hypothesized causes emphasized by proponents of competing views. The content of a particular client's insights and emergent "unconscious" could therefore be better predicted from knowledge of the therapist's belief system than from the client's actual social learning
history.

It eventually became apparent that if progress in understanding human behavior was to be accelerated, more stringent requirements would have to be applied in evaluating the adequacy of explanatory systems. Theories must demonstrate predictive power, and they must accurately identify causal factors, as shown by the fact that varying the postulated determinants produces related changes in behavior.

The attribution of behavior to inner forces can perhaps be likened to early explanatory schemes in other branches of science. At one time diverse chemical reactions were supposedly caused by movements of a material substance called phlogiston, physical objects were internally propelled by intangible es. sences, and physiological functioning was ascribed to the action of humors. Developments in learning theory shifted the focus of causal analysis from hypothesized inner determinants to detailed examination of external influences on responsiveness. Human behavior was extensively analyzed in terms of the stimulus events that evoke it and the reinforcing consequences that alter it. Researchers repeatedly tributed to that response patterns, generally atelimined to underlying forces, could be induced, nal sources of reinstated simply by varying exterled many psychologists, especially proponents of causes of behaviorism, to the view that the but in environmental fore found not in the organism

The idea that man's actions are under external control, though amply documented, was not enthusiastically received for a variety of reasons. To most people it unfortunately implied a one-way influence process that reduced man to a helpless reactor to the vagaries of external rewards and punishments. The view that behavior is environmentally deternined also appeared to contradict firm, but ill-founded, beliefs that people possess generalized personality traits leading them to behave in a consistent manner, however variable the social influences.

A more valid criticism of the extreme behavioristic position is that, in a vigorous effort to eschew spurious inner causes, it neglected determinants of man's behavior arising from his cognitive functioning. Man is a thinking organism possessing capabilities that provide him with some power of self-direction. To the extent that traditional behavioral theories could be faulted, it was for providing an incomplete rather than an inaccurate account of human behavior.

In the social learning view, man is neither driven by inner forces nor buffeted helplessly by environmental influences. Rather, psychological functioning is best understood in terms of a continuous reciprocal interaction between behavior and its controlling conditions. The social leaming theory outlined in this paper places special emphasis on the important roles played by vicarious, symbolic, and self-regulatory processes, which receive relatively little attention even in most contemporary theories of leaming. These differences in goveming processes carry certain implications for the way one views the causes of human bchavior

Traditional theories of leaming generally depict behavior as the product of directly experienced response consequences. In actuality, virtually all learning phenomena resulting from direct experiences can occur on a vicarious basis through observation of other people's behavior and its consequences for them. Man's capacity to learn by observation enables him to acquire large, integrated units of behavior by example without having to build up the pattems gradually by tedious trial and error. Similarly, emotional responses can be developed observationally by witnessing the affective reactions of others undergoing painful or pleasurable experiences. Fearful and defensive behavior can be extinguished vicariously by observing others engage in the feared activities without any adverse consequences. And behavioral inhibitions can be induced by seeing others punished for their actions.

Man's superior cognitive capacity is another factor that determines, not only how he will be affected by his experiences, but the future direction his actions may take. People can represent external influences symbolically and later use such representations to 
guide their actions; they can solve problems symbolically without having to enact the various alternatives; and they can foresee the probable consequences of different actions and alter their behavior accordingly. These higher mental processes permit both insightful and foresightful behavior.

A third distinguishing feature of man is that he is capable of creating self-regulative influences. By managing the stimulus determinants of given activities and producing consequences for their own actions, people are able to control their own behavior to some degree. As illustrated later, cognitive and self-regulative influences often serve important functions in causal sequences. The remainder of this paper is devoted to a detailed social learning analysis of how patterns of behavior are acquired and how their expression is continuously regulated by the interplay of self-generated and other sources of influences.

\section{Learning by Direct Experience}

In the social learning system, new patterns of behavior can be acquired through direct experience or by observing the behavior of others. The more rudimentary form of learning, rooted in direct experience, is largely governed by the rewarding and punishing consequences that follow any given action. People are repeatedy confronted with situations with which they must deal in one way or another. Some of the responses that they try prove unsuccessful, while others produce more favorable effects. Through this process of differential reinforcement successful modes of behavior are eventually selected from exploratory activities, while ineffectual ones are discarded.

It is commonly believed that responses are automatically and unconsciously strengthened by their immediate consequences. Simple performances can be altered to some degree through reinforcement without awareness of the relationship between one's actions and their outcomes. However, man's cognitive skills enable him to profit more extensively from experience than if he were an unthinking organism. Within the framework of social leaming theory, reinforcement primarily serves informative and incentive functions, although it also has responsestrengthening capabilities.

\section{Informative Function of Reinforcement}

During the course of learning, people not only perforn responses, but they also observe the differential consequences accompanying their various actions. On the basis of this informative feedback, they develop thoughts or hypotheses about the types of behavior most likely to succeed. These hypotheses then serve as guides for future actions [Dulany \& O'Connell 1963]. Accurate hypotheses give rise to successful performances, whereas erroneous ones lead to ineffective courses of action. The cognitive events are thus selectively strengthened or disconfirmed by the differential consequences accompanying the more distally occurring overt behavior. In this analysis of learning by experience, reinforcing consequences partly serve as an unarticulated way of informing performers what they must do in order to gain beneficial outcomes or to avoid punishing ones.

\section{Motivational Function of Reinforcement}

Because of man's anticipatory capacity, conditions of reinforcement also have strong incentive-motivational effects. Most human behavior is not controlled by immediate external reinforcement. As a result of prior experiences, people come to expect that certain actions will gain them outcomes they value, others will have no appreciable effects, and still others will produce undesired results. Actions are therefore regulated to a large extent by anticipated consequences. Homeowners, for instance, do not wait until they experience the misery of a burning house to buy fire insurance; people who venture outdoors do not ordinarily wait until discomforted by a torrential rain or a biting snowstorm to decide what to wear; nor do motonists usually wait until inconvenienced by a stalled automobile to replenish gasoline.

Through the capacity to represent actual outoomes symbolically, future consequences can be converted into current motivators that influence behavior in much the same way as actual consequences. Man's cognitive skills thus provide him with the capabiity for both insightful and foresightful behavior.

\section{Cognitive Mediation of Reinforcement Effects}

A great deal of research has been conducted on whether behavior is learned through the automatic action of consequences or whether the effects of reinforcement are cognitively mediated. Most of these studies have employed verbal conditioning situations in which subjects converse freely or construct sentences and the experimenter rewards certain classes of words but ignores all others. Changes in the incidence of reinforced verbalizations are then examined as a function of whether the participants were aware that their verbal utterances were selec tively reinforced and whether they recognized the types of words that produced reinforcement. 


\section{Albert Bandura}

Spielberger and De Nike [1966], proponents of an exclusively cognitive view of learning, measured subjects' awareness at periodic intervals throughout the verbal conditioning session. They found that subjects displayed no rise in the number of reinforced responses as long as they remained unaware of the reinforcement contingency, but they suddenly increased their output of appropriate responses upon discovering what types of words were rewarded. Dulany [1962, 1968] similarly found that reinforcing consequences were ineffective in modifying subjects' behavior as long as they were unaware of what they had to do to produce rewarding outcomes. These authors concluded that leaming cannot take place without awareness of what is being reinforced. Dulany, who outlined this position in a formal way, contended that the acquired response information gives rise to intentions or self-instructions to produce the required behaviors, the strength of the tendency depending on the incentive value of the consequences. Neither these findings nor the generalizations went uncontested.

Earlier studies by Postman and Sassenrath [1961], who also examined the temporal relation between emergence of awareness and changes in responsiveness, found that reinforcement produced small but significant improvements in performance prior to awareness, but subjects sharply increased appropriate responses after they hit upon the correct solution. Leaming, they concluded, can occur without awareness, albeit slowly and quite inefficiently. The resultant increase in correct responses makes it easier to discern what is wanted; once the discovery has been made, the appropriate behavior is readily performed, given adequate incentives. A sudden rise in correct responding with discovery of the reinforcement contingencies is generally regarded as insightful behavior.

The discrepant findings concerning the relationship between awareness and behavior change largely reflected how adequately awareness was measured. Spielberger and De Nike [1966] assessed at infrequent intervals during the learning task (after twenty-five trials) whether subjects figured out the correct responses. Subjects may, therefore, have discerned the reinforcement contingency late in the insight block of trials after a noticeable increase in performance was produced by reinforcement in the absence of awareness. By measuring awareness at shorter intervals, Kennedy [1970, 1971] demonstrated that this is precisely what happens. When data are plotted in twenty-five-trial blocks, awareness seems to precede behavior change, but when these same data are plotted in five- or ten-trial blocks, perform- ance gains precede awareness for subjects who later recognize the correct types of responses.

Whether emergence of awareness is accompanied by increases, decreases, or no change in performance largely depends on the reward value of the response consequences. People who are aware of appropriate responses in a given situation and who value the outcomes they produce change their behavior in the reinforced direction. On the other hand, those who are equally aware of the reinforcement contingencies but who devalue either the required behavior or the reinforcers not only remain uninfluenced but may even respond in an oppositional manner.

\section{Reinforcing Effects of Response Consequences}

Verbal conditioning procedures are adequate for demonstrating that awareness can facilitate changes in behavior, but they are ill-suited for resolving the basic question of whether awareness is a prerequisite for learning or performance change. The limitations are twofold: first, the verbalizations that are modified already exist in the subjects' repertoires so that the task does not involve response learning. Second, since both the responses and their outcomes are observable, experimenters have to rely on subjects' verbal reports of unknown reliability to figure out who is aware of what.

The question of whether learning must be consciously mediated is answered most decisively by studies in which either the reinforced responses or their effects are not attributable to awareness because the action-outcome relationship cannot be observed. Hefferline and his associates [Hefferline \& Keenan 1963, Hefferline, Keenan, \& Harford 1959] and Sasmor [1966] successfully modified the behavior of adults through reinforcement even though the latter were unable to observe their rewarded responses. In these studies the occurrence of visibly imperceptible muscular responses, detected by the experimenter through electronic amplification, is reinforced either by monetary reward or by termination of unpleasant stimuflation. Unseen responses increase substantially during reinforcement and decline abruptly after reinforcement is withdrawn. As might be expected, none of the people could identify the response that produced the reinforcing consequences.

In the preceding investigation; the appropriate responses were unobservable but the reinforcers were. Experiments have been conducted with animals in which the correct responses are noticeable but their reinforcing consequences are not [Chambers 1956, Coppock \& Chambers 1954, Coppock, Headlee, \& 
Hood 1953]. Results of such studies likewise show that responses can be automatically strengthened through selective reinforcement operating below the level of awareness.

Evidence that elementary performances can be increased through reinforcement without the mediating effects of awareness does not mean that people can learn to respond in accordance with relatively complicated principles in this manner as well. For an illustration of how rule-govemed behavior is under cognitive control, visualize a task in which subjects are presented with words varying in length, to which they must provide a correct number. Let us select an arbitrary rule wherein the correct number is obtained by subtracting the number of letters in a given word from 97 , dividing the remainder by 3 , and then multiplying the result by 5 . In this situation, appropriate responses are derived from a highorder rule,

$$
R=\frac{97-N \times 5}{3},
$$

requiring a three-step transformation of the external stimulus. To achieve errorless performances, one must perform accurately several mental operations in a particular sequence. An unthinking organism is unlikely to show any performance gains, however long its responses may be reinforced.

The overall evidence reveals that response consequences can be informative, motivating, and reinforcing. Therefore, in any given instance, contingent reinforcement may produce changes in behavior through any one or more of the three processes. People can learn some patterns of behavior by experiencing rewarding and punishing consequences, but if they know what they are supposed to do to secure desired outcomes, they profit much more from such experiences. As shown later, while reinforcement is a powerful method for regulating behaviors that have already been learned, it is a relatively inefficient way of creating them.

\section{Learning through Modeling}

Although behavior can be shaped into new patterns to some extent by rewarding and punishing consequences, learning would be exceedingly laborious and hazardous if it proceeded solely on this basis. Environments are loaded with potentially lethal consequences that befall those who are unfortunate enough to perform dangerous errors. For this reason it would be ill-advised to rely on differen- tial reinforcement of trial-and-error performances i teaching children to swim, adolescents to drive autc mobiles, and adults to develop complex occupatione and social competencies. Apart from questions c survival, it is difficult to imagine a socialization prc cess in which the language, mores, vocational activi ties, familial customs, and the educational, religiou: and political practices of a culture are taught to eacl new member by selective reinforcement of fortui tous behaviors, without benefit of models who exem plify the cultural patterns in their own behavior.

Most of the behaviors that people display ar. leamed, either deliberately or inadvertently, throug] the influence of example. There are several reason why modeling influences figure prominently in hu man learning in everyday life. When mistakes ar costly or dangerous, new modes of response can b. developed without needless errors by providing com petent models who demonstrate how the requirec activities should be performed. Some complex be haviors, of course, can be produced only through the influence of models. If children had no opportunity to hear speech, for example, it would be virtually impossible to teach them the linguistic skills tha constitute a language. It is doubtful that one coulc ever shape intricate individual words, let alont grammatical speech, by differential reinforcement of random vocalizations. Where novel forms of behavior can be conveyed only by social cues, modeling is an indispensable aspect of learning. Even in instances where it is possible to establish new response patterns through other means, the process of acquisition can be considerably shortened by providing appropriate models. Under most circumstances, a good example is therefore a much better teacher than the consequences of unguided actions.

A number of different theories have been proposed over the years to explain how people learn by observing the behavior of others. Major tenets of these alternative views, and their empirical status, are discussed at length elsewhere [Bandura 1971b]. The social leaming analysis of observational leaming differs from contemporary learning interpretations principally in the locus of response integration, in the role played by cognitive functions, and in the manner in which reinforcement influences observational learning.

\section{Nonmediated Stimulus-Response Theories}

There was no research to speak of on modeling processes until the classic publication Social Learning and Imitation by Miller and Dollard [1941]. They advanced the view that in order for imitative 


\section{Albert Bandura}

learning to occur observers must be motivated to act, they must be provided with an example of the desired behavior, they must perform responses that match the example, and their imitative behavior must be positively reinforced. In experiments conducted to test these assumptions, a model always chose one of two boxes that contained two rewards, and observers received one of the rewards whenever they went to the same box. Observers not only learned to follow the model, but they generalized copying responses to new situations, to new models, and to different motivational states.

These experiments were widely accepted as demonstrations of imitative learning, although they represent only a special form of discrimination placelearning. The model's actions simply informed children where to go but did not teach them any new behavior. Had a light or some other informative cue been used to indicate the correct box, the model's behavior would have been irrelevant and perhaps even a hindrance to efficient performance. Observational response learning, on the other hand, is concerned with how people organize behavioral elements to form new response patterns exemplified by others. Since the theory proposed by Miller and Dollard requires a person to display imitative responses before he can learn them, it accounts more adequately for the performance of previously established matching responses than for their acquisition. It is perhaps for this reason that publication of their research monographs, which contained many provocative ideas, aroused only a passing interest. Despite the prevalence and powerful influence of example in the development and regulation of human behavior, traditional accounts of learning contain little or no mention of modeling processes.

The operant conditioning analysis of modeling [Baer \& Sherman 1964, Skinner 1953, Gewirtz \& Stingle 1968] relies entirely upon the standard threecomponent paradigm $S^{d} \longrightarrow R \longrightarrow S^{r}$, where $S^{d}$ denotes the modeled stimulus, $R$ represents an overt matching response, and $S^{r}$ designates the reinforcing stimulus. Except for deletion of the motivational requirement, Skinner's explanation posits the same necessary conditions (that is, cue, response, reinforcement) for imitation originally proposed by Miller and Dollard. Observational learning, according to the operant view, is presumably achieved through differential reinforcement. When responses corresponding to the model's actions are positively reinforced and divergent responses either nonrewarded or punished, the behavior of others comes to function as cues for matching responses.

The scheme above does not appear to be appli- cable to observational leaming where an observer does not overtly perform the model's responses in the setting in which they are exhibited, reinforcements are not administered either to the model or to the observer, and whatever responses have been thus acquired are not displayed for days, weeks, or even months. Under these conditions, which represent one of the most prevalent forms of social learning, two of the factors $\left(R \longrightarrow S^{r}\right)$ in the three-element paradigm are absent during acquisition, and the third factor ( $S^{d}$, or modeling stimulus) is typically missing from the situation when the observationally leamed response is first performed. Like the Miller and Dollard theory, Skinner's analysis clarifies thow similar behavior that a person has previously leamed can be prompted by the actions of others and the prospect of reward However, it does not explain how a new matching response is acquired observationally in the first place. As shown later, such leaming occurs through symbolic processes during exposure to the modeled activities before any responses have been performed or reinforced.

\section{Social Learning Analysis of Observational Learning}

Social learning theory assumes that modeling influences produce learning principally through their informative functions and that observers acquire mainly symbolic representations of modeled activities rather than specific stimulus-response associations [Bandura 1969a, 1971a]. In this formulation, modeling phenomena are governed by four interrelated subprocesses.

Attentional processes. A person cannot leam much by observation if he does not attend to, or recognize, the essential features of the model's behavior. One of the component functions in learning by example is therefore concerned with attentional processes. Simply exposing persons to models does not in itself ensure that they will attend closely to them, that they will necessarily select from the model's numerous characteristics the most relevant ones, or that they will even perceive accurately the aspects they happen to notice.

Among the numerous factors that determine observational experiences, associational preferences are undoubtedly of major importance. The people with whom one regularly associates delimit the types of behavior that one will repeatedly observe and hence learn most thoroughly. Opportunities for learning aggressive behavior obviously differ markedly for members of delinquent gangs and of Quaker groups. Within any social group some members are likely 


\section{Social Learning Theory}

to command greater attention than others. The functional value of the behaviors displayed by different models is highly influential in determining which models will be closely observed and which will be ignored. Attention to models is also channeled by their interpersonal attraction. Models who possess interesting and winsome qualities are sought out, whereas those who lack pleasing characteristics tend to be ignored or rejected, even though they may excel in other ways.

Some forms of modeling are so intrinsically rewarding that they can hold the attention of people of all ages for extended periods. This is nowhere better illustrated than in televised modeling. Indeed, models presented in televised form are so effective in capturing attention that viewers learn the depicted behavior regardless of whether or not they are given extra incentives to do so [Bandura, Grusec, \& Menlove 1966].

Retention processes. A person cannot be much influenced by observation of a model's behavior if he has no mernory of it. A second major function involved in observational learning concerns long. term retention of activities that have been modeled at one time or another. If one is to reproduce a model's behavior when the latter is no longer present to serve as a guide, the response patterns must be represented in memory in symbolic form. By this means past influences can achieve some degree of permanence.

Observational learning involves two representational systems-an imaginal and a verbal one. During exposure, modeling stimuli produce, through a process of sensory conditioning, relatively enduring, retrievable images of modeled sequences of behavior. Indeed, under conditions where stimulus events are highly correlated, as when a name is consistently associated with a given person, it is virtually impossible to hear the name without experiencing imagery of the person's physical characteristics. Similarly, reference to activities (golfing, skiing), places (San Francisco, Paris), and things (one's automobile, Washington Monument) that one has previously observed immediately elicits vivid imaginal representations of the absent physical stimuli.

The second representational system, which probably accounts for the notable speed of observational learning and long-term retention of modeled contents by humans, involves verbal coding of observed events. Most of the cognitive processes that regulate behavior are primarily verbal rather than visual. The route traversed by a model can be acquired, retained, and later reproduced more accurately by verbal coding of the visual information into a sequence of right and left turns (for example, RLRRL) than b. reliance upon visual imagery of the itinerary. Ob servational learning and retention are facilitated $b$ : such codes because they carry a great deal of in formation in an easily stored form.

After modeled activities have been transformec into images and readily utilizable verbal symbols these memory codes serve as guides for subsequen reproduction of matching responses. That symbolic coding can enhance observational learning is showr by studies conducted both with children [Bandura Grusec, \& Menlove 1966, Coates \& Hartup 1969] anc with adults [Bandura \& Jeffery 1971, Gerst 1971] Observers who code modeled activities into eithes words, concise labels, or vivid imagery learn anc retain the behavior better than those who simply observe or are mentally preoccupied with othes matters while watching the performance of others

In addition to symbolic coding, rehearsal serves as an important memory aid. People who mentally re. hearse or actually perform modeled patterns of behavior are less likely to forget them than are those who neither think about nor practice what they have seen. Some of the behaviors that are learned observationally cannot be easily strengthened by overt enactment either because they are socially prohibited or because the necessary appartus is lacking. It is therefore of considerable interest that mental rehearsal of modeled activities can increase their retention [Bandura \& Jeffery 1971, Michael \& Maccoby 1961$]$.

Some researchers [Gewirtz \& Stingle 1968] have been especially concerned about the conditions that produce the first imitative responses on the assumption that they help explain observational learning at later stages of development. There is some reason to question whether initial and later imitations have equivalent determinants. In early years imitative responses are evoked directly and immediately by models' actions. In later periods, imitative responses are usually performed in the absence of the models long after their behavior has been observed. Immediate imitation does not require much in the way of cognitive functioning because the behavioral reproduction is externally guided by the model's actions. By contrast, in delayed imitation, the absent modeled events must be internally represented, and factors such as symbolic transformation and cognitive organization of modeling stimuli and covert rehearsal, which facilitate retention of acquired contents, serve as determinants of observational leaming. The difference between physically prompted and delayed imitation is analogous to drawing a picture of one's automobile when it is at hand, and from memory. 


\section{Albert Bandura}

In the latter situation, the hand does not automatically sketch the car; rather, one must rely on memory guides, mainly in the form of mental images.

Motoric reproduction processes. The third component of modeling is concerned with processes whereby symbolic representations guide overt actions. To achieve behavioral reproduction, a learner must put together a given set of responses according to the modeled patterns. The amount of observational learning that a person can exhibit behaviorally depends on whether or not he has acquired the component skills. If he possesses the constituent elements, he can easily integrate them to produce new patterns of behavior, but if the response components are lacking, behavioral reproduction will be faulty. Given extensive deficits, the subskills required for complex performances must first be developed by modeling and practice.

Even though symbolic representations of modeled activities are acquired and retained, and the subskills exist, an individual may be unable to coordinate various actions in the required pattern and sequence because of physical limitations. A young child can leam observationally the behavior for driving an automobile and be adept at executing the component responses, but if he is too short to operate the controls he cannot maneuver the vehicle successfully.

There is a third impediment at the behavioral leve] to skillful reproduction of modeled activities that have been learned observationally. In most coordinated motor skills, such as golf and swimming, performers cannot see the responses that they are making; hence, they must rely on ill-defined proprioceptive cues or verbal reports of onlookers. It is exceedingly difficult to guide actions that are not easily observed or to identify the corrective adjustments needed to achieve a close match of symbolic model and overt performance. In most everyday learning, people usually achieve rough approximations of new patterns of behavior by modeling and refine them through self-corrective adjustments on the basis of informative feedback from performance.

Reinforcement and motivational processes. A person can acquire, retain, and possess the capabilities for skillful execution of modeled behavior, but the learning may rarely be activated into overt performance if it is negatively sanctioned or otherwise unfavorably received. When positive incentives are provided, observational learning, which previously remained unexpressed, is promptly translated into action [Bandura 1965]. Reinforcement influences not only regulate the overt expression of matching be- havior, but they can affect the level of observational learning by controlling what people attend to and how actively they code and rehearse what they have seen.

For reasons given above, the provision of models, even prominent ones, will not automatically create similar patterns of behavior in others. If one is interested merely in producing imitative behavior, some of the subprocesses included in the social leaming analysis of modeling can be disregarded. A model who repeatedly demonstrates desired responses, instructs others to reproduce them, physically prompts the behavior when it fails to occur, and then administers powerful rewards will eventually elicit matching responses in most people. It may require 1,10 , or 100 demonstration trials, but if one persists, the desired behavior will eventually be evoked. If, on the other hand, one wishes to explain why modeling does or does not occur, a variety of determinants must be considered. In any given instance lack of matching behavior following exposure to modeling influences may result from either failure to observe the relevant activities, inadequate coding of modeled events for memory representation, retention decrements, motoric deficiencies, or inadequate conditions of reinforcement.

\section{Locus of Response Integration in Observational Learning}

New patterns of bchavior are created by organizing constituent responses into certain patterns and sequences. Theories of modeling differ on whether the response integration occurs mainly at central or at peripheral levels. Operant conditioning formulations [Baer \& Sherman 1964, Gewirtz \& Stingle 1968] assume that response elements are selected out of overt performances by providing appropriate antecedent stimuli and by rewarding actions that resemble the modeled behavior and ignoring those that do not. The response components presumably thus extracted are sequentially chained by the influ. ence of reinforcement to form more complex units of behavior. Since, in this view, behavior is organized into new patterns in the course of performanci learning requires overt responding and immediatc reinforcement.

According to social learning theory, behavior is learned, at least in rough form, before it is performed. By observing a model of the desired behavior, an individual forms an idea of how response components must be combined and temporally sequenced to produce new behavioral configurations. 
The representation serves as a guide for behavioral reproduction. Observational learning without performance is abundantly documented in modeling studies using a nonresponse acquisition procedure [Bandura 1969, Flanders 1968]. After watching models perform novel modes of response, observers can later describe the entire pattern of behavior with considerable accuracy, and given the appropriate conditions, they often achieve errorless behavioral reproductions on the first test trial.

It is commonly believed that controversies about the locus of learning cannot be satisfactorily resolved because learning must be inferred from performance. This may very well be the case in experimentation with animals. To determine whether a rat has mastered a maze one must run him through it. With humans, there exists a reasonably accurate index of learning that is independent of motor performance. To measure whether a human has learned a maze by observing the successful performances of a model, one need only ask him to describe the correct pattern of right and left turns. Such an experiment would undoubtedly reveal that people can learn through modeling before they perform.

\section{Role of Reinforcement in Observational Learning}

Another issue in contention concerns the role of reinforcement in observational leaming. As previously noted, reinforcement-oriented theories [Baer \& Sherman 1964, Miller \& Dollard 1941, Gewirtz \& Stingle 1968] assume that imitative responses must be reinforced in order to be learned. Social learning theory, on the other hand, distinguishes between learning and performance of matching behavior. Observational learning, in this view, can occur through observation of modeled behavior and accompanying cognitive activities without extrinsic reinforcement. This is not to say that mere exposure to modeled activities is, in itself, sufficient to produce observational learning. Not all stimulation that impinges on individuals is necessarily observed by them, and even if attended to, the influence of model- ing stimuli alone does not ensure that they will be retained for any length of time.

Anticipation of reinforcement is one of several factors that can influence what is observed and what goes unnoticed. Knowing that a given model's behavior is effective in producing valued rewards or averting negative consequences can enhance observational learning by increasing observers' attentiveness to the model's actions. Moreover, anticipated reinforcement can strengthen retention of what has been learned observationally by motivating people to code and to rehearse modeled responses that have high value. Theories of modeling primarily differ in the manner in which reinforcement influences observational leaming rather than in whether reinforcement may play a role in the acquisition process. As shown in the schematization below, the issue in dispute is whether reinforcement acts backward to strengthen preceding imitative responses and their association to stimuli or whether it facilitates leaming through its effects on attentional, organizational, and rehearsal processes. It would follow from social leaming theory that a higher level of observational learning would be achieved by informing observers in advance about the payoff value for adopting modeled patterns of behavior than by waiting until observers happen to imitate a model and then rewarding them for it.

In social learning theory reinforcement is considered a facilitative rather than a necessary condition because there are factors other than response consequences that can influence what people will attend to. One does not have to be reinforced, for example, to hear compelling sounds 'or to look at prominent visual displays. Hence, when people's attention to modeled activities can be gained through physical means, the addition of positive incentives does not increase observational learning [Bandura, Grusec, \& Menlove 1966]. Children who intently watched modeled actions on a television screen in a room darkened to eliminate distractions later displayed the same amount of imitative leaming regardless of whether they were informed in advance that correct imitations would be rewarded or given

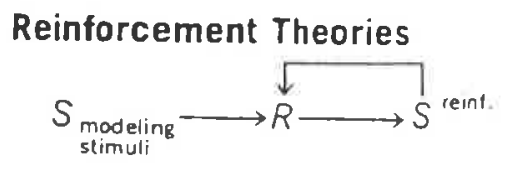

Social Learning Theory

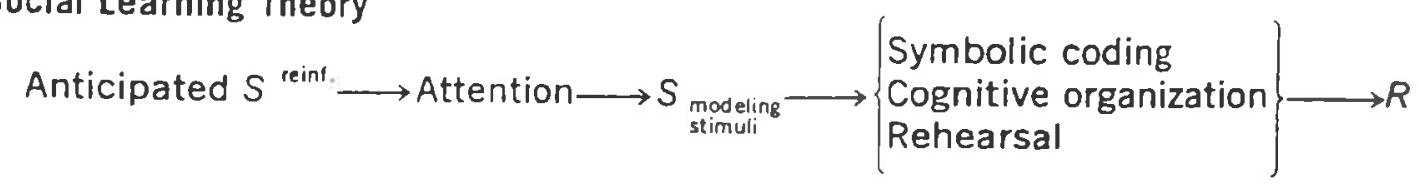




\section{Albert Bandura}

no prior incentives to learn the modeled performances. Anticipated reinforcement would be expected to exert greatest influence on observational learning under self-selection conditions where people can choose whom they will attend to and how intensively they observe their behavior.

Both operant conditioning and social leaming theories assume that whether or not people choose to perform what they have learned observationally is strongly influenced by the consequences of such actions. In social learning theory, however, behavior is regulated, not only by directly experienced consequences from external sources, but by vicarious reinforcement and self-reinforcement.

\section{The Modeling Process and Transmission of Response Information}

A major function of modeling stimuli is to transmit information to observers on how to organize component responses into new patterns of behavior. This response information can be conveyed through physical demonstrations, through pictorial representation, or through verbal description.

Much social learning occurs on the basis of casual or studied observation of exemplary models. As linguistic skills are developed, verbal modeling is gradually substituted for behavioral modeling as the preferred mode of response guidance. By performing sequences of actions as described in instructional manuals, people can leam how to assemble and operate complicated mechanical equipment, how to behave in a variety of unfamiliar social situations, and how to perform vocational and recreational tasks in a skillful manner. Verbal modeling is used extensively because one can convey through words an almost infinite variety of complex behaviors that would be exceedingly difficult and time consuming to portray behaviorally.

Another influential source of social learning is the abundant and varied symbolic modeling provided in television, films, and other pictorial displays. There is a large body of research evidence showing that both children and adults can acquire attitudes, emotional responses, and new patterns of behavior as a result of observing filmed or televised models [Bandura 1969a, Flanders 1968, Lumsdaine 1961]. Considering the large amount of time that people spend watching televised models, mass media may play an influential role in shaping behavior and social attitudes. With further developments in communication technology, it will be possible to have almost any activity portrayed on request at any time on remote television consoles [Parker 1970]. As such forms of symbolic modeling are increasingly used, parents, teachers, and other traditional role models may assume a less prominent role in social learning.

The basic modeling process is the same regardless of whether the desired behavior is conveyed through words, pictures, or live actions. Different forms of modeling, however, are not always equally effective. It is frequently difficult to convey through words the same amount of information contained in pictorial or live demonstrations. Some forms of modeling may also be more powerful than others in commanding attention. Children, or adults for that matter, rarely have to be compelled to watch television, whereas verbal characterizations of the same activities would fail to hold their attention for long. One might also expect observers who lack conceptual skills to benefit less from verbal modeling than from behavioral demonstrations.

\section{Scope of Modeling Influences}

In many instances the behavior displayed by exemplary models must be learned in essentially the same form. For example, driving automobiles or performing surgical operations permit little, if any, departure from established practices. In addition to transmitting fixed repertoires of behavior, modeling influences can, contrary to common belief, create generative and innovative behavior as well.

In studying more complex forms of modeling, persons observe models respond to different stimuli in accordance with a preselected rule or principle. Observers are subsequently tested under conditions where they can behave in a way that is stylistically similar to the model's disposition, but they cannot mimic his specific responses. To take an example, a model constructs from a set of nouns sentences containing the passive voice. Children are later. instructed to generate sentences from a different set of nouns with the model absent, and the incidence of passive constructions is recorded. In this higher form of modeling, observers must abstract common features exemplified in diverse modeled responses and formulate a rule for generating similar patterns of behavior. Responses performed by subjects that embody the observationally derived rule are likely to resemble the behavior that the model would be inclined to exhibit under similar circumstances, even though observers had never witnessed the model's behavior in these new situations.

A number of studies have been conducted demonstrating how response-generative rules can be transmitted through modeling. Young children who had no formal grammatical knowledge altered their 
syntactic style in accord with the rules guiding the modeled verbal constructions [Bandura \& Harris 1966, Liebert, Odom, Hill, \& Huff 1969, Rosenthal \& Whitebook 1970]. In addition, modeling influences have been successful in modifying moral judgmental orientations [Bandura \& McDonald 1963, Cowan, Langer, Heavenrich, \& Nathanson 1969], delay of gratification patterns [Bandura \& Mischel 1965, Stumphauzer 1969], and styles of information seeking [Rosenthal, Zimmerman, \& Durning 1970]. Researchers have also begun to study how modeling influences alter cognitive functioning of the type described by Piaget and his followers [Rosenthal \& Zimmerman 1970, Sullivan 1967].

The broader effects of modeling are further revealed in studies employing several models who display different patterns of behavior. Observers may select one or more of the models as the primary source of behavior, but they rarely restrict their imitation to a single source, nor do they adopt all of the characteristics of the preferred model. Rather, observers generally exhibit relatively novel responses representing amalgams of elements from different models [Bandura, Ross, \& Ross 1963a]. Paradoxical as it may seem, innovative patterns can emerge solely through modeling. Thus, within a given family samesex siblings may develop distinct personality characteristics as a result of adopting different combinations of parental and sibling attributes. A succession of modeling influences, in which observers later become sources of behavior for new members, would most likely produce a gradual imitative evolution of novel patterns that might bear little resemblance to those exhibited by the original models. In homogeneous cultures, where alt models display similar modes of response, imitative behavior may undergo little or no change across successive models. It is diversity in modeling that fosters behavioral innovation.

The discussion thus far has been concerned solely with the process of learning through modeling. A second major function of modeling influences is to strengthen or to weaken inhibitions of responses that observers have previously leamed [Bandura 1971b]. The effects that models have on behavioral restraints are largely determined by observation of rewarding and punishing consequences accompanying models" responses. As a result of seeing a model's actions punished, observers tend to inhibit behaving in a similar way. Conversely, observing models engage in threatening or prohibited activities without experiencing any adverse consequences can reduce inhibitions in observers. Such disinhibitory effects are most strikingly revealed in recent therapeutic applications of modeling principles [Bandura 1971a]. In these studies, people who dread and avoid certain activities are able to perform them in varying degrees after observing others perform the feared behaviors repeatedly without any harmful effects.

The actions of others can also serve as social cues that influence how others will behave at any given time. Response facilitation by modeling can be distinguished from observational learning and disinhibition by the fact that the model's actions neither teach new behaviors nor reduce inhibitions, because the behavior in question, which already exists, is socially sanctioned and therefore is unencumbered by restraints. Inhibitory and disinhibitory effects of modeling are examined later in the context of vicarious reinforcement, while social facilitation effects are given detailed consideration in the discussion of stimulus control of behavior.

Modeling influences can have additional effects, though these may be of lesser importance. The behavior of models directs observers' attention to the particular objects used by the performer. As a result, observers may subsequently use the same objects to a greater extent, though not necessarily in an imitative way. In one experiment, for example, children who had observed a model pummel a large doll with a mallet not only imitated this specific aggressive action but spent more time pounding other things with a mallet than did those who did not see a person handle this particular instrument [Bandura 1962]. Research findings, considered together, disclose that modeling influences can serve as teachers, as inhibitors, as disinhibitors, as response elicitors, as stimulus enhancers, and as emotion arousers.

\section{Regulatory Processes}

A comprehensive theory of behavior must explain not only how response patterns are required but how their expression is regulated and maintained. In social leaming theory, human functioning relies on three regulatory processes. They include stimulus, cognitive, and reinforcement control. For explanatory purposes, these control functions are discussed separately, although in reality they are closely interrelated.

\section{Stimulus Control}

To function effectively a person must be able to anticipate the probable consequences of different events and courses of action and regulate his be- 


\section{Albert Bandure}

havior accordingly. Without a capacity for anticipatory or foresightful behavior, man would be forced to act blindly in ways that might eventually prove to be highly unproductive, if not perilous. Information about probable consequences is conveyed by environmental stimuli, such as traffic signals, verbal communications, pictorial messages, distinctive places, persons, or things, or the actions of others.

In the earliest years of development, environmental stimuli, except those that are inherently painful, exert little or no influence on infants and young children. As a result of paired experiences, either direct or vicarious, formerly neutral stimuli begin to acquire motivating and response-directive properties. Stimulus control over emotions and actions is established in both instances through association, but they differ in what gets associated.

\section{Stimulus Control of Physiological and Emotional Responsiveness}

Physiological responses can be most readily brought under the control of environmental stimuli by having two stimulus events occur contiguously. If a formerly neutral stimulus is closely associated with one that is capable of eliciting a given physiological response, the former stimulus alone gradually acquires the power to evoke the physiological response or a fractional component of it. Although some types of automatic responses are more difficult to condition than others, almost every form of somatic reaction that an organism is capable of making, including changes in respiration, heart rate, muscular tension, gastrointestinal secretions, vasomotor reactions, and other indices of emotional responsiveness, has been classically conditioned to innocuous stimuli [Kimble 1961]. Environmental events can likewise acquire the capacity to control cortical activity through association with either external evocative stimuli or direct brain stimulation [John 1967]. Conditioning is by no means confined to events in the external environment. In recent years researchers [Razran 1961, Slucki, Adam, \& Porter 1965] have been able to condition physiological reactions as well as defensive behaviors to variations in the intensity of visceral stimulation from internal organs.

The conditioning process described above has important implications for the understanding of, among other things, psychosomatic disorders, defensive behavior, and evaluative reactions having an affective component. In the psychosomatic field Dekker, Pelser, and Groen [1957] established asthmatic attacks in two patients by pairing formerly ineffective stimuli with allergens that evoked respiratory dys functions. A careful analysis of the situations ir which other patients regularly experienced asthmatic attacks revealed that a varied array of stimuli had acquired controlling value; these included, among other things, radio speeches by influential politicians, children's choirs, the national anthem, elevators, goldfish, caged birds, the smell of perfume, waterfalls, bicycle races, police vans, and horses. Once the conditioned stimuli had been identified in a particular case, Dekker and Groen [1956] were able to induce attacks of asthma by presenting the evocative stimuli in actual or pictorial form.

A great deal of human behavior is under aversive stimulus control. In this form of emotional learning, persons, places, and events become endowed with anxiety-arousing value through association with painful experiences. A prime function of most anticipatory behavior is to provide protection against potential threats. Once established, defensive behavior is exceedingly diffoult to eliminate because it derives self-reinforcing power from its capacity to reduce distress. Any protective activities that remove or avoid discomfort aroused by conditioned threats are thereby strengthened even though the fears may no longer be realistically justified. This process is graphically illustrated by the apocryphal case of a compulsive who, when asked by a psychiatrist why he incessantly snapped his fingers, replied that it kept ferocious lions away. When informed that obviously there were no lions in the vicinity, the compulsive client replied, "See, it works." Inhibitions and avoidance responses commonly regarded as neurotic (for example, phobias and obsessivecompulsive rituals) are similarly strengthened by their capacity to lessen subjectively distressing but objectively nonexistent threats. To the extent that tormerly aversive situations are successfully avoided, individuals prevent themselves from discovering that current conditions of reinforcement may differ substantially from those in the past, when their anxiety reactions were appropriate.

In an early study Miller [1948] showed how subjective threats can motivate, and fear reduction reinforce, a variety of defensive behaviors in a currently benign environment. Animals were shocked in a white compartment of a shuttle box where they quickly learned to escape the painful stimulation by running through an open door into a black compartment. The formerly neutral white cues thus acquired aversive properties so that the animals continued to run when placed in the white box even after the shocks had been completely discontinued. To examine 
1 further acquisition and self-perpetuation of new defensive reactions in the absence of any physical danger, Miller placed the animals in the white compartment with the door closed to prevent escape. The door could be released, however, by rotating a wheel. Wheel tuming was rapidly learned and maintained by fear reduction. When environmental conditions were further changed so that wheel turning no longer released the door, but the animal could escape the compartment by pressing a bar, the former response was quickly discarded while the latter became strongly established. An animal psychiatrist observing these winded animals dashing through compartments, turning wheels, and pressing bars to avoid nonexistent shocks would justifiably diagnose them as suffering a serious psychological disorder. Their behavior was clearly out of touch with reality.

Symbolic conditioning. Conditioning principles would have limited explanatory power if emotional responses could be established only through direct physical experiences. It is not uncommon for people to display strong emotional reactions toward certain things or classes of people on the basis of little or no personal contact with them. Such responses are frequently developed on the basis of higher processes in which symbolic stimuli that have acquired positive or negative valence through direct association with primary experiences serve as the basis for further
conditioning.

Emotion-arousing words often function as the vehicle for symbolic conditioning. Words that conjure up feelings of revulsion and dread can be effectively used to create new fears and hatreds; conversely, words arousing positive emotions can endow associated events with pleasing qualities. In laboratory investigations of symbolic conditioning neutral sylla. Jes have been found to take on negative value through repetitive pairing with adjectives having negative connotations (for example, ugly, dirty), whereas these same items are evaluated as pleasant after they have been associated with positively conditioned words such as beautiful and happy [Insko \& Oakes 1966, Staats \& Staats 1957]. Preexisting evaluative reactions toward familiar names of persons and nations have also been significantly altered through conditioning methods using emotional words Gale and stimuli [Staats \& Staats 1958]. Moreover, that emotionally charged [1970] provide some evidence that emotionally charged words can condition autoneutral stimuli. Es well as evaluative reactions to toward objects singledive responses occur not only they also tend to generalize along established asso- ciative networks, thus resulting in widespread effects. Das and Nanda [1963], after associating meutral syllables with the names of two aboriginal tribes, conditioned positive and negative reactions to the syllables by pairing them with affective words. The tribes took on positive and negative values in accordance with the evaluative responses developed to the syllables with which they had been associated.

Symbolic conditioning may be achieved to some extent through pictorial stimuli having affective properties. Geer [1968], for example, conditioned autonomic responses to tones with photographs of victims of violent death. The role of conditioning processes is perhaps nowhere more dramatically illustrated than in the marked cross-cultural variations in the physical attributes and adomments that become sexual arousers. What is invested with arousal properties in one society-corpulence or skinniness, upright hemispherical breasts or long pendulous ones, shiny white teeth or black pointed ones, distorted ears, noses, or lips, broad pelvis and wide hips or narrow pelvis and slim hips, light or dark skin color -may be neutral or repulsive to members of another social group. A bold experiment by Rachman [1966] on how fetishes might be acquired throws some light on symbolic conditioning of sexual arousal. After a photograph of women's boots was repeatedly associated with slides of sexually stimulating nude females. males exhibited sexual arousal (as measured by penile volume change) to the boots alone and generalized the conditioned sexual responses to other types of black shoes. Needless to say, these unusual sexual reactions were thoroughly eliminated at the conclusion of the study. Consistent with the latter findings, McGuire, Carlisle, and Young [1965] advance the view that deviant sexuality often develops through masturbatory conditioning in which aberrant sexual fantasies are endowed with strong erotic value through repeated association with pleasurable experiences from masturbation.

Vicarious conditioning. While many emotional responses are learned on the basis of direct experience, much human learning undoubtedly occurs through vicarious conditioning. The emotional responses of another person, as conveyed through vocal, facial, and postural manifestations, can arouse strong emotional reactions in observers. Affective social cues most likely acquire arousal value as a result of correlated experiences between people. That is, individuals who are in high spirits tend to treat others in amiable ways, which arouse in them similar pleasurable affects; conversely, when individuals are dejected, ailing, distressed, or angry, 


\section{Albert Bandura}

others are also likely to suffer in one way or another. This speculation receives some support in a study by Church [1959], who found that expression of pain by an animal evoked strong emotional arousal in animals that had suffered pain together; it had much less emotional effect on animals that had undergone equally painful experiences but unassociated with suffering of another member of their species, and it left unmoved animals that were never subjected to any distress.

In vicarious conditioning, events take on evocative properties through association with emotions aroused in observers by affective experiences of others. In laboratory studies of this phenomenon, an observer hears a tone and shortly thereafter he sees another person exhibit pain reactions (actually feigned) as though he were severely shocked [Berger 1962]. Observers who repeatedly witness this sequence of events begin to show emotional responses to the tone alone even though no pain is ever inflicted on them. In everyday life, of course, pain may be witnessed from a variety of sources. Observation of failure experiences and the sight of terrified people threatened by menacing animals have, for instance, served as arousers for emotional learning [Bandura, Blanchard, \& Ritter 1969, Craig \& Weinstein 1965].

Despite the importance of vicarious leaming, there has been surprisingly little study of the factors determining how strongly people can be affectively conditioned through the experiences of others. The nature of the relationship between the observer and the sufferer is undoubtedly an influential factor. People are generally less affected emotionally by the adversities of strangers than by the suffering and joy of those close to them and on whom they depend. Observers' sensitivity to expressions of suffering, derived from their past social experiences, may be another contributor. Bandura and Rosenthal [1966], for example, found that the degree to which observers were emotionally aroused affected their level of vicarious conditioning. Those who were under moderate emotional arousal displayed the highest rate and most enduring conditioned autonomic responses, whereas those who were either quite calm or highly aroused showed the weakest vicarious conditioning. Apparently, anguished reactions proved so upsetting to observers who themselves were beset by high arousal that they diverted their attention from the suffering person and sought refuge in distracting thoughts of a calming nature.

It is evident from the preceding discussion that emotional learning is much more complex than is commonly assumed. Emotional responses can be brought under the control of intricate combinations of internal and external stimuli that may be either closely related to, or temporally remote from, physica] experiences. The fact that stimulus events can be endowed with emotion-arousing potential on a vicarious basis further adds to the complexity of conditioning processes. Additionally, it will be shown later that formerly neutral stimuli can acquire evocation properties through association with thought-produced arousal. Once conditioned stimuli have acquired eliciting power, this capacity transfers to other sets of stimuli that possess similar physical characteristics, to semantically related cues, and even to highly dissimilar stimuli that happen to be associated in people's experiences.

By associating the term behaviorism with odious images of salivating dogs and animals driven by carrots and sticks, critics of behavioral approaches skillfully employ Pavlovian conditioning procedures on their receptive audiences to endow this point of view with degrading properties. The fact that valuation of places, persons, and things is affected by one's emotional experiences, whether they be fearful, humiliating, moumful, or pleasurable, does not mean that such conditioning outcomes reflect a base animal process. To expect people to remain unaffected by paired experiences is to require that they be less than human. Moreover, to be sensitive to the consequences of one's actions indicates intelligence rather than subhuman functioning.

\section{Cognitive Control of Conditioning Phenomena}

Both popular accounts and psychological descriptions of conditioning phenomena convey the impression that emotional responsiveness is conditioned automatically through paired stimulation occurring in a certain temporal relationship. This, view is typically reinforced by diagrammatic portrayal of the process as a nonmediated one in which conditioned stimuli are directly connected to responses evoked by unconditioned stimuli. Results of several lines of research indicate that, in humans, conditioning phenomena. cannot be fully understood without encompassing the influence of cognitive control.

Studies of the relationship between awareness of paired events and degree of leaming reveal that conditioning involves more than simply linking stimuli to new responses through contiguous association. Fuhrer and Baer [1965] report an experiment in which one tone was always followed by shock but a different tone was presented alone. People who recognized that one of the tones signified shock responded emotionally whenever it appeared, whereas those who remained unaware of the stimulus con- 
tingencies did not. Other researchers have likewise shown that repetitive association of neutral and aversive stimuli does not produce conditioned emotional responses in people who fail to recognize that the two sets of events are related [Dawson \& Grings 1968, Dawson \& Satterfield 1969].

That awareness is a determinant of conditioning rather than vice versa is convincingly demonstrated by Chatterjee and Eriksen [1962]. People who were informed that shock would follow a particular word in a chain of associations quickly developed conditioned heart-rate responses. In contrast, subjects who were led to believe that the occurrence of shock was not related in any consistent way to their verbalizations evidenced no autonomic conditioning even though they repeatedly experienced the same paired stimulation as their aware counterparts.

The most striking evidence of cognitive control of conditioned responses is provided by studies comparing extinction of emotional reactions to conditioned stimuli in subjects who are informed that the stimuli are no longer followed by painful events and in those who are never told that the threat has ceased to exist. Induced awareness promptly abolishes conditioned autonomic responses [Grings \& Lockhart 1963, Notterman, Schoenfeld, \& Bersh 1952, Wickens, Allen, \& Hill 1963] and avoidance behavior [Lindley \& Moyer 1961, Moyer \& Lindley 1962], whereas uninformed subjects lose their fear only gradually.

Self-arousal interpretation of conditioning. According to social leaming theory, conditioned emotional responses are typically mediated through thought-produced arousal rather than being directly evoked by conditioned stimuli. The power to arouse emotional responses is by no means confined to external events. People can easily make themselves nauseated by imagining revolting experiences. They can become sexually aroused by generating erotic fantasies. They can frighten themselves by fearprovoking thoughts. And they can work themselves up into a state of anger by ruminating about mistreatment from offensive provocateurs. Indeed, Barber and Hahn [1964] found that imagined painful stimulation produced subjective discomfort and physiological responses similar to those induced by the actual painful stimulation. The incomparable Satchel Paige, whose extended baseball career provided many opportunities for anxious self-arousal, colorfully described the power that thoughts can exert over visceral functioning when he advised, "If your stomach disputes you lie down and pacify it with cool thoughts."

The findings reported in the preceding section are consistent with the self-arousal interpretation of con- ditioning. In aware individuals, events that forebode distress activate fear-arousing thoughts that produce emotional responses. On the other hand, those who, for one reason or another, fail to notice that the conditioned stimulus foreshadows pain do not conjure up frightening ideas. As a result, the conditioned stimulus rarely evokes emotional responses even though it is often paired with unpleasant experiences. Sudden disappearance of conditioned emotional responses following awareness that the threat has been removed is also explainable in terms of self-arousal processes. Given such knowledge, conditioned stimuli no longer activate frightening thoughts, and a major source of emotional responses is thus removed.

It follows from self-arousal theory that emotional conditioning can be achieved on a cognitive basis in the absence of physically painful experiences. Grings and others [Bridger \& Mandel 1964, Dawson \& Grings 1968] provide some evidence on this point. In their experiments, subjects are told that a given stimulus will sometimes be followed by shock, but except for a sample experience, this in fact never occurs. Formerly neutral stimuli acquire arousal capabilities through association with thought-produced emotional responses. That covert self-stimulation plays an influential role in this type of cognitively based conditioning is shown by Dawson [1966]. He reports that the level of emotional conditioning was positively related both to the degree to which subjects believed that they would be shocked and to the severity of pain they anticipated.

Although the development and extinction of conditioned emotional responses are subject to cognitive control, this does not mean that all conditioned responses are necessarily consciously mediated. The degree of cognitive control partly depends on the conditions under which the emotional responses are originally acquired. Bridger and Mandel [1964] found that autonomic conditioning was similar regardless of whether stimuli were associated with threat of shock alone or with threat combined with shock experiences. Emotional responses established on the basis of actual painful experiences, however, were less susceptible to cognitive control. Thoughtinduced conditioned responses promptly disappeared with the knowledge that shocks would no longer be forthcoming. By contrast, conditioned emotional responses originating in painful experiences persisted for some time despite awareness that the physical threat was completely removed.

These findings may be explained in several ways. It may mean that conditioned responses contain dual components, as Bridger and Mandel suggest. One of the components-created by self-arousal influences- 


\section{Albert Bandura}

is readily modifiable by having a person alter his thoughts. The second component may be a nonmediated one that is directly evoked by external stimuli and hence requires disconfirming experiences for its extinction. Snake phobics, for example, will instantaneously respond with fear at the sight of a coiled snake before they have time to cogitate about the potential dangers of reptiles.

An alternative interpretation is that in instances where people either have undergone distressing experiences or there is a remote chance that they might get hurt, external stimuli become such powerful elicitors of fear-provoking thoughts that they are not easily subject to voluntary control. To tell phobics who dread heights that they can gaze down safely from the rooftop of a tall building because of protective railings does not mean that they will be able to turn off thoughts about the horrendous things that could conceivably happen. Here fearfulness is still cognitively mediated but the individual is unable to control his thoughts, however safe the eliciting situations may be.

Nonmediational theories of conditioning assume that associated stimulus events must be registered in the nervous system of the organism. Studies examining the influence of awareness on conditioning should therefore obtain evidence that the input from the stimulus to be conditioned has in fact been received. It is not inconceivable that in experiments where, to reduce awareness, subjects' attention is diverted to irrelevant features of the situation, the conditioned stimuli may not be registered in a sufficiently consistent manner to produce stable conditioned responses. Neural responses to afferent input can be substantially reduced by focusing attention on irrelevant events. In neurophysiological studies by Hernández-Péon, Scherrer, and Jouvet [1956], for instance, auditory neural responses to a loud sound were virtually eliminated in cats when they gazed at mice, attentively sniffed fish odors, or received shocks that disrupted their attentiveness. Hom [1960] noted a similar weakening of neural responses to a light flash during active attention to other sights and sounds.

People who direct their attention to extraneous features may neither experience nor recognize the conditioned stimulus. Absence of conditioning, under such circumstances, may be erroneously attributed to lack of conscious recognition when, in fact, it derives from deficient sensory registration of the stimulus. Proof that awareness is necessary for learming would require evidence that, despite adequate neural registration of the paired environmental events, classical conditioning does not occur unless the relationship between the events is recognized.

Developmental theories of psychological functioning often draw sharp distinctions between associative and cognitive processes as though they represented independent functions. As noted above, cognitive influences can markedly affect performances regarded as associative in nature. Extent of cognitive control can, in turn, be influenced by asso. ciative factors. Mandel and Bridger [1967], for instance, demonstrated that awareness hastened fear extinction, but the speed with which aware subjects lost their apprehensions depended on how closely and in what order neutral and aversive stimuli were associated when the fear was first learned. Most changes in behavior undoubtedly result from the interactive effects of associative and cognitive influences.

\section{Disorders Arising from Inappropriate Stimulus Control}

The development of stimulus functions has considerable adaptive value, but unfortunately, as alluded to in some of the illustrative material, it can also create needless distress and constricting defensiveness. Dysfunctions of this sort can arise in several different ways. Events that happen to occur in the context of traumatic experiences but are in no way causally related to them sometimes take on aversive properties and produce inappropriate generalization of anxiety reactions. The following letter taken from the advice column of a newspaper illustrates such inappropriate generalization.

\section{Dear Abby:}

My friend fixed me up with a blind date and I should have known the minute he showed up in a bow tie that he couldn't be trusted. I fell for him like a rock. He got me to love him on purpose and then lied to me and cheated on me. Every time I go with a man who wears a bow tie, the same thing happens. I think girls should be warned about men who wear them.

\section{Against Bow Ties}

In this above example, the letter writer had generalized a whole pattern of social behavior to bow ties, a stimulus one would not expect to be routinely correlated with deceitfulness. To the extent that her anticipatory hostile actions evoke negative counterreactions in bow-tied men, her defensive behaviors create adverse experiences and are thereby selfperpetuated. Here the inappropriate behavior is maintained by a self-produced reality rather than 
one that had been in effect in the past but no longer exists under changed conditions of life.

Irrational defensive behaviors often occur on the basis of overgeneralization from events associated with traumatic experiences to others that are similar to them either physically or semantically. In the often quoted study by Watson and Rayner [1920], for example, several pairings of a rat and a loud sound produced in a young boy, not only marked fear of the rat, but the fear generalized widely to other furry objects including rabbits, dogs, fur coats, cotton, wool, and even human hair.

Clinical evidence exists that suggests that relatively innocuous stimuli may be invested with powerful aversive properties through semantic generalization. Walton and Mather [1963] report the case of a woman who suffered from obsessions about being dirty and spent much of her life performing incapacitating ygienic rituals.

The main feature was compulsive handwashing which appeared to arise from doubts about contamination of herself by dirt. After every daily activity or whenever she believed she may have touched something which had been handled by another person before her, she would wash her hands four or five times (taking fifteen minutes). Door knobs and taps were particularly anxiety-provoking as they were handled most frequently. Going to the toilet would always be followed by handwashing and additional scrubbing of the nails. Taking a bath and washing her hair would occupy several hours due to continual rewashing of herself, the bath, and the washbasin. To avoid contamination, she would ensure that she never brushed against walls or other people's clothing and she always kept her own clothes in a special place untouched by others. Any street or thoroughfare would be examined for patches of dirt. Many such activities, such as turning on taps and opening doors were delegated to her mother. She would in fact never venture outside the house alone lest she were required to handle something and there were no facilities for washing: Sitting on public seats was also difficult for her [p. 169].

The obsessive-compulsive behavior began with her severe guilt and feelings of "dirtiness" because of sexual relations in a love affair with a married man. Eventually, a wide range of stimuli related to urogenital activities and all forms of dirt became disturbing to her.

Maladaptive emotional responses can not only be created by unpleasant paired experiences, but they can be eliminated by therapeutic methods utilizing similar principles [Bandura 1969a, Franks 1969]. This is achieved by repeated exposure to threatening events without the occurrence of any adverse consequences. Several variant procedures have been devised and applied with relatively high success. In the extinction method disabling anxieties are removed by gradually exposing clients to progressively more frightening situations or through massive contact with what they fear. Some understandably loathe facing what they dread, thus requiring positive inducements. Therapies based on counterconditioning desensitize anxious people by presenting to them the things they fear together with anxiety neutralizers (for example, muscular relaxation, tranquilizing imagery, or the reassurance and security of a supportive person) capable of eliciting highly positive reactions. By reducing the level of anxiety arousal, positive activities allow persons to tolerate threats they might ordinarily avoid without experiencing them as unduly aversive. $A$ third major approach relies upon modeling procedures wherein anxiety disorders are eliminated by having anxious clients observe others engaging in threatening activities without experiencing any untoward consequences. After undergoing this form of treatment they lose their fears, they can engage in activities they formerly inhibited, and they develop more favorable attitudes toward the things they abhorred.

\section{Stimulus Control of Action}

The same actions can produce markedly different consequences, depending upon the time, the place, and the persons toward whom they are expressed. Driving through a busy intersection on a red signal, for example, will have painfully different effects from crossing on a green light. People therefore come to attend closely to stimuli that predict reinforcement and to ignore those that do not, and they utilize cues that signify probable consequences in regulating their behavior. Stimuli indicating that given actions will be punished or nonrewarded tend to inhibit their performance, whereas those signifying that the actions are permissible or rewardable facilitate their occurrence. The capacity to regulate responsiveness on the basis of information conveyed by antecedent stimuli about likely response consequences provides the mechanism for foresightful behavior.

Stimuli acquire controlling power by being correlated with differential response consequences. Traditional explanations of how stimulus control is developed focus primarily on direct training in which responses are reinforced only in the presence of certain cues but never in a different stimulus context. Stimulus control is undoubtedly established and maintained in many instances through correlation with experienced response consequences. However, man's symbolic capacity enables him to gain such 


\section{Albert Bandura}

information without having to perform responses and experience them rewarded, ignored, or punished under varied conditions. Much learning of this sort is achieved through verbal explanations that describe situations in which certain actions are regarded as appropriate or out of place. Moreover, as we shall see later, stimulus control can be effectively established by observing how the behavior of others is reinforced in different situations. Although people often guide their actions solely on the basis of what they have observed or been told, maintenance of verbally and vicariously produced stimulus control ordinarily requires periodic confirmation through direct experience.

Interpersonal behavior is partly regulated by characteristics of people that predict the consequences likely to accompany certain courses of action. Children often behave quite differently in the presence of their mothers and their fathers in accordance with their disciplinary practices. The following quotation provides a telling example of an autistic boy who freely expressed destructive behavior with his lenient mother but rarely did so in the presence of his father, who tolerated no aggression.

Whenever her husband was home, Billy was a model youngster. He knew that his father would punish him quickly and dispassionately for misbehaving. But when his father left the house, Billy would go to the window and watch until the car pulled out. As soon as it did, he was suddenly transformed. ... "He'd go into my closet and tear up my evening dresses and urinate on my clothes. He'd smash furniture and run around biting the walls until the house was destruction from one end to the other. He knew that I liked to dress him in nice clothes, so he used to rip the buttons off his shirts, and used to go in his pants [Moser 1965, p. 96].

In a formal study of social stimulus control Redd and Birnbrauer [1969] had one adult reward a group of seclusive children for playing cooperatively, while a second adult rewarded them equally regardless of their behavior. Later the mere appearance of the contingently rewarding adult evoked cooperative play, but the noncontingent adult exerted no influence on the children's behavior. When the adults reversed their reinforcement practices their power to elicit play behavior changed accordingly.

People frequently regulate their behavior on the basis of more subtle soeial cues. To take a common example, parents are quick to issue commands to their children, but they do not always see to it that their requests are heeded. Children are therefore inclined to ignore demands voiced in mild or moderate tones. The parents' mounting anger usually serves as the cue that they will enforce compliance so that only shouts produce results. Indeed, many households are run at a fairly high decibel level.

Of the numerous stimuli that influence how people will behave at any given moment, none is more ubiquitous or effective than the actions of others. People applaud when others clap, they laugh when others laugh, they exit from social functions when they see others leaving, and on countless other occasions their behavior is prompted and channeled by modeling stimuli.

The actions of others acquire controlling properties through selective reinforcement in much the same way as do physical and symbolic stimuli in nonsocial forms. When behaving like others produces rewarding outcomes, modeling cues become powerful determinants of analogous behavior; conversely, when matching actions are treated negatively but dissimilar behavior proves rewarding. models' responses prompt divergent performances in observers. Because people usually display modes of behavior that are appropriate and effective, following good examples is much more reinforcing than tedious trial and error. As a result, modeling cues generally assume high predictive value. Thus, by relying on the actions of knowledgeable models, a novice can behave appropriately in synagogues, in mosques, in saloons, at wedding ceremonies, and in countless other situations, without having to discover the acceptable conduct through shocked or pleased reactions to his unguided performances. The dictum "When in Rome do as the Romans do" underscores the functional value of modeling stimulus control.

People differ in the degree to which their behavior is guided by modeling influences, and not all models are equally effective in eliciting the types of behavior they themselves exemplify. Responsiveness to modeling influences is largely determined by three factors, which derive their power from correlation with conditions of reinforcement. These include the characteristics of the models, the attributes of the observer, and the response consequences associated with matching behavior.

With regard to model characteristics, those who have high status, prestige, and power are much more effective in evoking matching behavior in observers than models of low standing. The force of prestigeful example is well illustrated in a study of behavioral contagion conducted by Lippitt, Polansky, and Rosen [1952]. Children in summer camps rated each other in terms of their power to influence others. Observers then recorded the incidence and sources of behavioral contagion, defined as spontaneous imitation of the actions of another person where he displayed no 


\section{Social Learning Theory}

intent to get others to follow his example. The behavior of a few models who were attributed high power largely determined the conduct of the camp members. The influence of prestigeful modeling is demonstrated even more convincingly by Lefkowitz, Blake, and Mouton [1955]. Pedestrians were more likely to cross a street on a red light when they saw a presumably high-status person in executive attire do it than when the same transgression was performed by the same model dressed in soiled patched trousers, scuffed shoes, and a blue denim shirt.

It is not difficult to explain why model status facilitates matching behavior. The actions of models who have gained some status are more likely to be successful and hence have greater functional value for observers than the behavior of models who possess relatively low vocational, intellectual, and social competencies. In situations where people are uncertain about the wisdom of modeled courses of action, they rely on model characteristics and statusconferring symbols (for example, speech, dress, deportment, possession of material goods), which serve as tangible indicants of past successes. The effects of a model's prestige tend to generalize from one area of behavior to another, as when prominent athletes advise on breakfast cereals as though they were nutrition experts. Unfamiliar persons also gain influence by their similarity to models whose behavior proved successful in the past.

Some efforts have been made to identify the types of people who are most responsive to modeling influences. Observers who achieve better outcomes by following the examples of others than through their own independent behavior are readily susceptible to modeling influences. Therefore, those who have been frequently rewarded for imitative behavior and those who lack self-esteem, who feel incompetent, and who are highly dependent are especially prone to pattern their behavior after successful models [Bandura 1969b, Campbell 1961].

The preceding generalizations must be accepted with reservations because the functional value of modeled behavior overrides the influence of either model or observer characteristics. It is exceedingly unlikely that dull, anxious, and dependent students would gain more from observing skilled ski instructors, brain surgeons, or airline pilots than understudies who are bright, attentive, and self-assured. When modeled activities are highly valued, the more venturesome and talented observers benefit most from exposure to exemplary models. Laboratory studies reporting prosaic correlates of imitativeness typically employ inconsequential modeled behaviors that com- petent observers would have little incentive to leam.

The attributes of models exert greatest influence when it is unclear what consequences their behavior is likely to have. Observers must therefore rely on status cues that may have been correlated with reinforcement in their past experiences. A prestigeful or attractive model may induce a person to try a given course of action, but if the behavior should prove unsatisfactory, it will be discarded and the model's future influence diminished. For this reason studies in which response consequences are not evident may exaggerate the role played by model characteristics in the long-term control of social behavior.

In everyday life cues that predict the likely consequences of different actions appear as part of a bewildering variety of irrelevant events. To complicate matters further, the rules governing reinforcement often involve particular combinations of several environmental factors. To borrow an example from the study of conceptual behavior, a person is asked to sort a set of pictures that differ in a variety of ways into correct and incorrect piles without being told the relevant feature. Let us arbitrarily designate all pictures containing an adult drinking an alcoholic beverage as positive instances of the concept, and those that do not as negative instances. As the person sorts the pictures on the basis of provisional guesses, he observes which of his placements get rewarded and he eventually abstracts the common feature from the array of irrelevant stimuli. Response consequences are generally determined by the joint presence of several factors. Continuing with the above example, only pictures depicting drinking by an adult at home or in a bar, ir the evening, and in the company of others might be considered appropriate, whereas solitary or daytime drinking and imbibing in work settings would not. Here the reinforcement rule combines temporal, social, and situational cues. The important role played by cognitive processes in rule-regulated behavior is discussed later.

Defective stimulus control. Effective social functioning requires highly discriminative responsiveness, often to subtle variations in stimulus events. Some behavior disorders primarily reflect defective stimulus control, due either to faulty reinforcement practices or to a loss of such functions under stressful experiences. Rosenbaum [1953, 1956], for example, found that people were less able to distinguish critical from irrelevant features of the environment under strong than mild threat, and those prone to emotional arousal were most adversely affected in this regard.

Social behavior is extensively regulated by verbal cues. We influence people's actions in innumerable 


\section{Albert Bandura}

situations by suggestions, requests, commands, and written directives. Because of the importance of symbolic communication in human relationships, deficient or inappropriate responsiveness to verbal stimuli can have serious consequences. As part of a program to develop procedures for modifying psychotic behavior, Ayllon and his associates [Ayllon \& Haughton 1962, Ayllon \& Michael 1959] provide illustrations of defective verbal control. In one study, a group of schizophrenics with severe chronic eating problems were totally unresponsive to meal announcements or to persuasive appeals. Because of concern for their health, patients were escorted by nurses to the dining room, spoon-fed, tube-fed, and subjected to electroshock "therapy" and other forms of infantilizing and punitive treatments. It appeared that the nurses' coaxing, persuading, and feeding inadvertently reinforced the eating problems. Also, by rewarding nonresponsiveness to verbal requests, they lost their directive function. All social rewards for ignoring the announcement of mealtime and for refusals to eat were therefore withdrawn; following meal call, the dining room remained open for thity minutes and any patient who failed to appear during that time simply missed his meal. After these consequences were instituted, patients responded in a socially appropriate manner to meal calls and fed themselves.

In his studies of language leaming in autistic children, Lovaas [1967] shows how the influence of modeling stimuli can be negated by faulty reinforcement practices. Autistic children who lacked communicative speech imitated the therapist's verbalizations with high accuracy when rewards were made contingent upon correct speech reproductions. By contrast, when children were equally generously rewarded but without regard to the quality of their verbalization, their imitative behavior progressively deteriorated until it bore little resemblance to the verbal responses modeled for them by the therapist.

\section{Reinforcement Control}

An organism that responded foresightedly on the basis of informative environmental cues but remained unaffected by the results of its actions would be too obtuse to survive for long. In fact, behavior is extensively controlled by its consequences. Responses that cause unrewarding or punishing effects tend to be discarded, whereas those that produce rewarding outcomes are retained and strengthened. Human behavior therefore cannot be fully understood without examining the powerful influence of reinforcement control.
Traditional theories of reinforcement have been almost entirely concerned with demonstration of how behavior can be regulated by directly experienced consqeuences arising from external sources. Out of this circumscribed research interest grew the unfortunate impression that behavior theories view man as a manipulable autornaton with hardly any self-regulatory capacities. Social learning theory, while acknowledging the important responsive guiding role played by extrinsic feedback, posits a wider range of reinforcement influences. People are not only affected by the experiences created by their actions; they also regulate their behavior to some extent on the basis of observed consequences, as well as those they create for themselves. These three different forms of reinforcement control-direct, vicarious, and self-monitored-are considered next.

\section{External Reinforcement}

Some of the most impressive demonstrations of how behavior is controlled by its immediate consequences are found in the treatment of behavior disorders. Such studies usually employ an "intrasubject replication design" in which troublesome behavior is successively eliminated and reinstated by systematic variation of reinforcement contingencies. One case, selected from a large number reported by Harris, Wolf, and Baer [1964], illustrates the four-step procedure.

First, the person who is having difficulties is observed for a time to assess the incidence of the deviant behavior, the contexts in which it tends to occur, and the reactions it elicits from others. In the case under discussion, an extremely withdrawn boy spent about 80 per cent of his time secluded in isolated areas of the nursery school. Observation revealed that the teachers unwittingly reinforced his seclusiveness by paying a great deal of attention to him when he remained by himself, reflecting his feelings of loneliness, consoling him, and urging him to play with others. On the infrequent occasions when he happened to join other children, the teachers took no special notice.

In the second phase of the program a new set of reinforcement practices is instituted. Continuing with the above example, the teachers stopped rewarding solitary play with attention and support. Instead, whenever the boy sought out other children, a teacher joined the group and gave it her full attention. In a short time, the boy's withdrawal declined markedly and he was spending about 60 per cent of his time playing with other children.

After the desired changes have been produced, the 
original reinforcement practices are reinstated to determine whether the deviant behavior was in fact maintained by its social consequences. In this third stage, for example, the teachers behaved in their customary way, being inattentive to his sociability but responding with comforting ministrations when he was alone. The effect of this traditional "mental hygiene" approach was to drive the child back into seclusiveness. Clearly, social practices should be evaluated in terms of the effects they have on recipients rather than in terms of the humanitarian intent of the practitioners.

In the final phase, the therapeutic contingencies are reintroduced, the deviant patterns are eliminated, and the adaptive ones are generously rewarded until they then are adequately supported by their natural consequences. In the above case, the teachers gradually reduced their rewarding attentiveness as the boy derived increasing enjoyment from play activities with his peers. In follow-up observations he continued to enjoy his social relationships, which contrasted conspicuously with his previous seclusiveness.

Similar treatments conducted with both children and adults reveal that a wide variety of grossly deviant behaviors-including self-injurious actions, hypochondriacal and delusional preoccupations, infantile and regressive patterns, extreme withdrawal, chronic anorexia, psychogenic seizures, asthmatic attacks, psychotic tendencies, and countless other disorders of long standing-have been successfully eliminated, reinstated, and removed for a second time by altering the amount of social reinforcement they elicit from others.

The regulatory influence of reinforcement has been demonstrated not only with deviant conditions but with all other forms of behavioral functioning as well. Until recently it was widely believed that internal physiological states could be extemally aroused but were not subject to reinforcement control. In an ingenious series of studies the eminent psychologist Neal Miller [1969] succeeded in altering visceral responsiveness in animals, including changes in heart rate, blood pressure, blood flow, intestinal contractions, and even rate of urine formation by reinforcing the animals whenever physiological responses of a selected rate or magnitude occurred. The preciseness of reinforcement cont.ol is most impressively revealed in a study in which animals were rewarded for relatively greater volume flow of blood to one ear than to the other. The differential reinforcement produced corresponding changes in the amount of blood flow to the two ears.

Preliminary studies indicate that this line of research holds promise for advancing understanding of the development of psychosomatic disorders and their treatment. Voluntary control of one's own physiological functioning is achieved through instantaneous feedback techniques. In this procedure, people are told to maintain a given level of physiological responsiveness during which they are signaled with a tone or light whenever they achieve a desired state of body function. Dworkin and Miller [Miller, Di Cara, Solomon, Weiss, \& Dworkin 1970] found that a subject could increase and decrease his diastolic blood pressure to some degree by informative feedback of changes in selected directions. In a fascinating project, Kamiya [1968] succeeded in teaching people to control their alpha brain states (experienced as feelings of serene well-being) by monitoring their brain waves and sounding a tone when they reduced their brain waves to a rhythm between eight to twelve cycles per second. During alpha periods subjects felt relaxed, they exerted no mental effort, and they experienced no visual imagery.

Budzynski Stoyva, and Adler [1970] successfully applied the biofeedback method in treating tension headaches resulting from sustained contraction of scalp and neck muscles. Patients heard a tone with a frequency proportional to the electromyographic (EMG) activity in the monitored forehead muscles. They were instructed to keep the tone low by relaxing their facial muscles. As the patients became more adept at muscular relaxation, the criterion was increased in graded steps requiring progressively more relaxation to achieve low-pitched tones. Through this method patients who had experienced daily headaches over a period of several years quit tensing their facial muscles and eventually eliminated their headaches. The clinical applicability of biofeedback techniques will depend on the degree of voluntary control people can exert on their physiological responses. It would appear from preliminary findings that they possess greater self-regulatory capacities than was previously believed.

Reinforcement control of behavior is further shown by evidence that people behave quite differently de. pending on the pattern and frequency with which their actions are reinforced. Those who have been rewarded each time they respond are likely to become easily discouraged and to give up quickly when their efforts fail. On the other hand, individuals whose behavior has been reinforced intermittently tend to persist for a considerable time despite setbacks and only occasional success.

Intermittent reinforcement can take a variety of forms. Sometimes behavior is reinforced only after a specified period of time has elapsed (fixed-interval schedule), as in pay periods, eating schedules, and recreational cycles. When rewards occur on a fixed temporal basis, the payoff is the same regardless of 


\section{Albert Bandura}

the person's productivity; hence, behavioral output is relatively low. For this reason people are more often rewarded on the basis of the amount of work they accomplish rather than on the passage of time. In a fixed-ratio schedule a person must complete a given amount of work for each reinforcement. Because outcomes depend on one's own behavior, responsiveness remains high.

In everyday life most reinforcements occur not only periodically but in an irregular manner. For instance, superiors rarely check their employees' work at the same time each day, and achievements regarded as adequate on one occasion may be considered insufficient at another. Under variableinterval schedules individuals are reinforced at changeable times; in variable-ratio schedules the performances required for each reinforcement vary. Since in both instances the rewards occur unpredictably, variable schedules produce higher and more consistent performances than those in which outcomes occur with evident regularity. Even under variable schedules, outcomes occurring on a performance rather than on a time basis produce higher levels of responsiveness. Ferster [Ferster \& Skinner 1957] created a striking example of schedule influences by rewarding simultaneously the right-hand responses of a subject on a fixed-ratio and the lefthand responses on a variable-ratio schedule. The subject produced two remarkably different sets of performances, each corresponding to the typical response rates generated by these types of schedules.

As a further way of illustrating schedule control of behavior let us consider how patrons of the gambling devices at Las Vegas might behave under different systems of reinforcement. Given a fixed-interval schedule, where playing a slot machine produces a jackpot each time an hour has elapsed, patrons would deposit a coin and then sit around watching the clock until it was time to insert the next coin for the payoff. Under a fixed-ratio schedule requiring, for example, 25 plays to produce a jackpot, patrons would be seen busily stuffing slot machines at a high, stable rate. If the customary reinforcement was no longer forthcoming after an hour in the first case, and after 25 responses in the second, players would rapidly quit with loud complaints. On a variableinterval schedule-where players receive a jackpot on the average every hour but it can occur unpredictably after 10 minutes, a half hour, or 2 hours-they are likely to wait for a while immediately after gaining a jackpot and then play at a moderate, steady rate. Put on a variable-ratio schedule-where on the average every 25 th response produces a payoff but sometimes 5 responses are sufficient, whereas at other times 10,50 , or even as many as 200 responses may be needed to get a jackpot-players would continue cranking the machine at a rapid pace without a break until their money ran out, fatigue set in, or their spouses intervened. Since the variable-ratio schedule is most powerful in maintaining behavior at minimum costs, owners of gambling casinos understandably favor it. Behavior that has been reinforced on a thin variable-ratio schedule is exceedingly hard to extinguish because one's efforts are sustained by the belief that the actions will eventually prove successful and it takes a long time to realize that the rewards are no longer forthcoming.

In everyday life mixed schedules of reinforcement predominate, with both the number of unreinforced responses and the intervals between reinforcements continually changing. Drivers, for example, are not fined for every traffic violation. Speakers are not equally applauded every time they express their views. And scheduled activities do not always occur on time. Behavior is usually associated with variable outcomes because people are not always around to mediate the reinforcing consequences. Even when they are present, their preferences often differ so that the same actions may be applauded, ignored, or disapproved, depending on with whom one interacts.

The matter of reinforcement control is much more complicated than would appear from the discussion thus far. If people did not have the power of countercontrol, they could be impelled to do almost anything simply by amanging the appropriate consequences. In social interactions, however, participants are dependent upon each other to get what they want and consequently they have some power over each other. When conflicts arise, as they often do, compromise systems are adopted that are acceptable to both parties. As power disparities change, so do reinforcement systems. When employers enjoyed commanding positions, they paid their employees on a piece-rate basis representing various fixed-ratio schedules. As organized labor gained increasing power, it was able to negotiate interval schedules in which prescribed wages were guaranteed on a daily. weekly, monthly, and eventually on an annual basis. In order to ensure high performance, many employers combined ratio and interval schedules by paying fixed wages plus commissions based on individual or group productivity. It many other areas of functioning people understandably strive for power that would enable them to remove bothersome performance requirements for desired outcomes. Further illustrations are provided later of how the potential power of extemal reinforcement is weakened and counteracted by reciprocal control and by the influence of other reinforcement systems.

The opinion is often expressed that desired activi- 
ties should be performed for their own sake. It is feared that reinforcing practices may not only interfere with the development of self-determining characteristics but may render people so dependent upon extrinsic supports that they remain unresponsive without payoffs. Some of the more intemperate critics, whose own activities are generously reinforced by salaries, consulting fees, book royalties, and the applause of sympathetic audiences, consider the use of reinforcement to be manipulative and debasing.

The fact that behavior is controlled by its consequences is not a phenomenon created by behavioral scientists, any more than physicists are responsible for the laws of gravity. The process of natural selection has favored organisms adept enough to regulate their behavior on the basis of the effects it produces. Continuing with the above example, a social commentator might express moral indignation over gravitational control of behavior and denounce it as dehumanizing and degrading. A poetic view of man might be more flattering but it would in no way reduce the likelihood that people will continue to fall should they fling themselves off heights. The major purpose of psychological science is not to romanticize human behavior but rather to understand it.

Some of the criticisms that have been levied against reinforcement practices fail to recognize the complexity and the developmental changes in the consequences that influence behavior. At the earliest developmental levels, infants and young children are responsive only to immediate physical events, such as food, painful stimulation, and physical contact. It would be foolhardy for parents to rely on children's self-actualizing tendencies to keep them out of fires, electric outlets, or busy thoroughfares. In the course of development, as physically rewarding experiences are repeatedly associated with expressions of interest and approval, and punishments with disapproval and withdrawal of interest, the social reactions themselves eventually acquire reinforcing properties. At this higher level of psychological functioning behavior is extensively governed by symbolic social reinforcements. It would be a rare, unfeeling person who could remain totally indifferent to the sentiments of others.

Some child-rearing authorities popularized the view that healthy personality development can be achieved only through "unconditioned love." If this principle were, in fact, applied, parents would respond warmly and affectionately regardless of how their children behaved--whether or not they treated others maliciously, stole whatever they wanted, amassed a record of failing grades, showed contempt for the wishes and rights of others, and demanded immediate gratification of their desires. Unconditioned love, were it possible, would make children directionless, irresponsible, asocial, and quite unlovable. Most readers are probably acquainted with families where parents who attempted to approximate this condition succeeded in producing "selfactualized" tyrants. Guideless interest is clearly not enough. Fortunately, the vast majority of parents are not indiscriminate dispensers of affection. Being human, they tend to be displeased with reprehensible actions. It also comes as no surprise that some of the strongest advocates of unconditional regard are quite selective in their own social responsiveness, approving things they like and disapproving those they do not [Murray 1956, Truax 1966]. And recipients of this differential treatment accommodate to their preferences.

There are a number of symbolic reinforcers, other than social responses, that take on reinforcing functions. Money, having exchange value for countless things that people want, is a dependable and durable generalized reinforcer of behavior. When exemplary achievements are recursently rewarded, qualitative differences in performance acquire reinforcing value. After signs of progress and merited attainment become a source of personal satisfaction, knowledge that one has done well can function as a reward. However, the reinforcement ensuing from successful results is most likely mediated through self-reinforcement. For this reason, correctness feedback on tasks that are personally devalued or very simple is unlikely to have much reinforcing value. On the other hand, attairments that exceed personal standards of what constitutes a worthy performance activate positive self-evaluations, whereas inadequate accomplishments produce self-dissatisfaction.

Many of the activities that enhance competency are initially tiresome and uninteresting and it is not until one acquires proficiency in them that they assume reinforcing functions. During initial stages of skill development children are often coerced to perform required activities by demands and threats that, more often than not, instill antipathies rather than competencies. This prevalent problem can be largely avoided by rewarding children's efforts, both socially and tangibly, until the behavior is developed to the stage at which it produces more natural reinforcing effects. Thus, for example, children may temporarily require extrinsic encouragement to teach them how to read, but after they become skilled at it they read on their own for the enjoyment it provides. Many other forms of behavior, such as verbal facility and manual skills, which enable people to deal more 


\section{Albert Bandura}

effectively with their environment, do not require arbitrary rewards to sustain them.

Some performances are also partially maintained by the sensory reinforcement they produce. Infants, for example, repeatedly perform responses for certain sounds and sights and older children and adults spend long hours playing musical instruments that create pleasing sensory feedback. When activities are sustained by the sensory effects they naturally create, the phenomenon is usually designated as intrinsic reinforcement. This process is often distinguished from extrinsic reinforcement, where the outcomes, such as social approval or monetary rewards, represent arbitrary response consequences. The reinforcing value of most forms of sensory feedback is learned rather than inherently furnished. Indeed, many of the things that people enjoy doing for their own sake, whether playing atonal music or writing compositions, were probably experienced originally as somewhat aversive. As a result of repeated exposure, skill acquisition through initial extrinsic reinforcement, and investment of self-esteem rewards in merited performances, however, the activities eventually take on positive value.

The highest level of autonomy is achieved when individuals regulate their own behavior by selfevaluative and other self-produced consequences. The paramount role played by self-reinforcement in controlling human actions is given detailed consideration in a later section of this paper. Behavior is least susceptible to the vagaries of externally occurring reinforcement when effective consequences are either intrinsically related to the behavior or are self-administered. Paradoxically, the types of symbolic and self-regulatory mechanisms that humanistically oriented commentators consider to be antithetical to behavioral approaches are, in fact, most successfully developed by practices derived from principles of social learning.

\section{Vicarious Reinforcement}

Human functioning would be exceedingly ineffcient, not to mention dangerous, if behavior were controlled only by directly experienced consequences. Fortunately, people can profit greatly from the experiences of others. In everyday situations reinforcement typically occurs within a social context. That is, people repeatedly observe the actions of others and the occasions on which they are rewarded, ignored, or punished. Despite the fact that observed rewards and punishments play an influential role in regulating behavior, vicarious reinforcement has, until re- cent years, been essentially ignored in traditional theories of learning.

There is a second reason why the study of vicarious reinforcement is critical to the understanding of reinforcement influences. Observed consequences provide reference standards that determine whether a particular reinforcer that is externally administered will serve as a reward or as a punishment. Thus, for example, the same compliment is likely to be discouraging to persons who have seen similar performances by others more highly acclaimed, but rewarding when others have been less generously
praised.

Research on the relational character of reinforcing events has shown that the same consequence can have rewarding or punishing effects on behavior depending upon the nature, frequency, or generosity with which one's performances were previously reinforced. However, incentive contrast effects, resulting from discrepancies between observed and directly experienced consequences, have received relatively
little attention.

\section{Vicarious Punishment}

Vicarious reinforcement is defined as a change in the behavior of observers resulting from seeing the response consequences of others. Vicarious punishment is indicated when observed negative consequences reduce people's tendency to behave in similar or related ways. This phenomenon has been studied most extensively with respect to aggressive behavior. In the typical experiment [Bandura 1965 Bandura, Ross, \& Ross 1963b] children are shown a flm depicting a model engaging in novel aggressive behaviors that are either rewarded, punished, or unaccompanied by any evident consequences. Witnessing aggression punished usually produces less imitative aggression than seeing it obtain social and material success or go unnoticed.

Because of the variety and complexity of social influences, people are not always consistent in how they respond to aggressive behavior. Rosekrans and Hartup [1967] examined the effects of discrepant observed consequences on imitative aggression. Children who saw assaultive behavior consistently rewarded were most aggressive, those who saw it consistently punished displayed virtually no imitative behavior, while those who saw aggression sometimes rewarded and sometimes punished exhibited a moderate level of aggressiveness.

A second major set of experiments has been concerned with how vicarious punishment affects peo- 


\section{Social Learning Theory}

ple's willingness to violate prohibitions. Walters and his associates [Walters, Leat, \& Mezei 1963, Walters \& Parke 1964, Walters, Parke, \& Cane 1965] have shown that witnessing peer models punished for violating prohibitions increases observers' inhibition of transgressive behavior as compared with conditions in which modeled transgressions are either rewarded or simply ignored. Results of a comparative study by Benton [1967] indicate that, under some conditions, observed and directly experienced punishment may be equally effective in reducing deviant behavior. Children who observed peers punished for engaging in prohibited activities later showed the same amount of response inhibition as the punished transgressors.

An interesting experiment by Crooks [1967] reveals that lower species are also highly susceptible to observed punishments. After being tested for the extent to which they handled play objects, monkeys observed distress vocalizations sounded (through a tape recorder) whenever a model monkey touched a particular object; they also witnessed the model's contacts with a control object accompanied by the distress vocalizations played backwards, which did not sound like a pain reaction. In a subsequent test the observing animals played freely with the control item but actively avoided objects that supposedly produced painful experiences for another animal.

In all of the preceding studies the model was punished either verbally or physically by someone else. In many instances persons respond with selfpunitive and self-devaluative reactions to their own behavior that may be considered permissible, or even commendable, by others. Numerous experiments, which are discussed later, demonstrate that witnessing punishments self-administered by a model has inhibitory effects on observers with respect to unmerited achievements. Observation of self-punishment by a model has been shown by Porro [1968] to exert similar effects on transgressive behavior. For children who viewed a filmed model exhibit selfapproving responses to her transgressions, 80 per cent subsequently handled toys they were forbidden to touch, whereas the transgression rate was only 20 per cent for children who had observed the same model respond self-critically toward her own transgressions.

\section{Vicarious Positive Reinforcement}

Behavior can be enhanced as well as reduced by observed outcomes. Vicarious positive reinforcement is evident when observers display an increase in behavior for which they see others rewarded. Results of numerous experiments generally show that observed rewards produce a greater increase in similar responding than if the exemplified actions have no evident consequences. In the case of behavior that is ordinarily disapproved, however, seeing transgressions go unpunished seems to heighten analogous actions in observers to the same degree as witnessing models rewarded [Bandura 1965, Walters \& Parke 1964, Walters, Parke, \& Cane 1965]. To the extent that absence of anticipated punishment conveys permissiveness and allays fears, behavioral restraints are thereby reduced and transgressive actions are performed more readily.

\section{Relative Effectiveness of Direct and Vicarious Reinforcement}

How do observed consequences compare with directly experienced ones in their power to influence behavior? The answer to this question partly depends upon whether one assesses effects in terms of what is learned or what is performed. By watching the types of consequences produced by different actions in various settings, observers can learn the responses considered appropriate in given situations. Observers generally leam faster than reinforced performers, especially on tasks requiring conceptual behavior [Berger 1961, Hillix \& Marx 1960, Rosenbaum \& Hewitt 1966]. It is not diffcult to find reasons for the relative superiority of vicarious reinforcement. Performers may be impeded in discerning which of their actions lead to success by the need to create, to select, and to enact responses and by the emotional arousal resulting from experienced rewards and punishments. Observers, on the other hand, can give their undivided attention to discovering the correct solutions.

The relative power of vicarious and direct reinforcements is reversed with respect to their motivational effects, as reflected in the capacity to maintain effortful behavior over a long period. One would not recommend to employers, for example, that they maintain the productivity of their employees by having them witness a small group of workers receive pay checks at the end of each month. Seeing others rewarded may temporarily enhance responsiveness but it is unlikely by itself to have much sustaining power. Observation of other people's outcomes, however, can have a continuing influence on the effectiveness of direct reinforcement by providing a standard for judging whether the reinforcements one customarily receives are equitable, beneficent, or wnfair. Since both direct and vicarious reinforcements in- 


\section{Albert Bandura}

evitably occur together in everyday life, the interactive effects. of these two sources of influence on human behavior are of much greater significance than their independent controlling power. This assumption is borne out by evidence that seeing how others are reinforced can significantly increase or reduce the effectiveness of direct rewards and punishments in changing observers' responsiveness [Condrell 1967, Ditrichs, Simon, \& Greene 1967, Marlatt 1968].

Consistent with the preceding findings, explanations of social behavior emphasize relative rather than absolute reinforcement in determining the level of productivity and discontent within a society. Disadvantaged people may be rewarded more generously than in the past but still experience greater discouragement and resentment because the more affluent members of society make more rapid prog'ress, so that the disparity between the groups widens.

\section{Explanation of Vicarious Reinforcement}

Vicarious reinforcement is simply a descriptive term that does not explain how observed consequences produce their psychological effects. Social learning theory posits several different mechanisms by which witnessed rewards and punishments alter the actions, feelings, and thoughts of others [Bandura 1971c]. A vicarious reinforcement event may vary in a number of aspects, including the characteristics of the recipient and the reinforcing agents, the type and intensity of consequences, their justifiability, the situation in which reinforcements are administered, and the reactions of the participants. The number and type of mechanisms that are operative in any given instance will therefore depend upon the particular combination of these component factors.

One explanation of vicarious reinforcement is in terms of the informative function of observed outcomes. Response consequences accruing to others convey information to observers about the types of actions that are likely to be approved or disapproved. Given knowledge about probable response consequences, people will generally do the things they have seen well received and avoid those that they
have seen punished.

The same behavior can produce markedly different consequences depending on the setting in which it is performed. What is permissible in a nightclub may be censurable in a church. Hence, adaptive functioning requires not only response information but knowledge about what actions are appropriate in what setting. In modeling experiments where performers are rewarded for responding in a given con- text but ignored or punished for exhibiting the same behavior in a different situation, observers learn to discriminate critical features in their environment. [McDavid 1964, Wilson 1958]. In this way, vicarious reinforcement increases responding to stimuli correlated with observed rewards and decreases responding to stimuli signifying negative response consequences.

Observed reinforcement is not only informative but can also have incentive motivational effects. Seeing others reinforced can function as a motivator by arousing in observers expectations that they will be similarly rewarded for analogous performances. An experiment reported by Bruning [1965] illustrates how variations in the size of observed rewards, while providing equivalent information about the types of responses required for reinforcement, produce different levels of responsiveness through their motivational effects on observers. Children who had observed a performer generously rewarded subsequently responded more rapidly when they received smaller rewards for the same actions, whereas when observed rewards were smaller than the ones observers later received, they worked more slowly. These unexpected findings were attributed by Bruning to the energizing effects of frustration in the undercompensated condition, and to satiation in the beneficent treatment. The frequency with which others were rewarded has also been shown to affect how long observers will persist before they give up when their efforts are never reinforced [Berger \& Johansson 1968, Rosenbaum \& Bruning 1966]. Variations in the generosity with which other people are reinforced thus determines the speed, the vigor, and the persistence with which others behave.

Models generally exhibit emotional reactions while undergoing rewarding or punishing experiences. Observers are easily aroused by the emotional expressions of others. It was previously shown how vicariously elicited emotions can become conditioned either to the modeled behavior or to environmental stimuli that are regularly associated with performers' distress reactions. As a result of vicarious emotional conditioning, the negatively valenced stimuli or the matching responses are likely to frighten and to inhibit observers. Emotional arousal and behavioral inhibitions can also be extinguished by having fearful observers watch performers engaging in threatening activities without experiencing any adverse consequences. Vicarious conditioning and extinction of emotional arousal may therefore partially account for increases and decreases in responsiveness that result from observing affective consequences accruing to
models. 


\section{Social Leaming Theory}

In everyday situations people not only see the consequences of another's behavior but how he responds to his treatment. There is some evidence, presented by Ditrichs, Simon, and Greene [1967], that the performer's responsiveness to reinforcement signifcantly affects how observers later react when they themselves are rewarded for displaying similar behavior. Children who observed models give progressively more hostile responses for social approval later increased their own output of hostile responses under positive reinforcement, whereas when models gave progressively fewer rewarded hostile responses or reacted in random fashion, observers did not increase their expression of hostility even though they were positively reinforced whenever they did so. Susceptibility to direct reinforcement influences is thus increased by observed positive responsiveness and reduced by observed resistance.

In addition to the aforementioned effects of vicarious reinforcement, social status can be conferred on performers by the manner in which their behavior is reinforced. Punishment tends to devalue the model and his behavior, whereas the same model assumes emulative qualities when his actions are praised and otherwise rewarded [Bandura, Ross, \& Ross 1963b, Hastorf 1965]. Modification of model status, in turn, intuences the degree to which observers pattern their own actions after behavior exemplified by different models. There are conditions, of course, where observed punitive treatment enhances rather than lowers the recipient's social status. People who risk punishment for upholding their basic rights and beliefs gain the admiration not only of their peers but of others as well, especially when the protest is directed at social practices that violate the professed values of society. It is for this reason that authoritative agencies are usually careful not to discipline deviators in ways that might martyr them.

Observed reinforcements can alter the valuation of reinforcing agents as well as recipients. When societal agents misuse their power to reward and punish, they undermine the legitimacy of their authority and generate strong resentment. Under these conditions seeing inequitable punishment, rather than prompting compliance, may free incensed observers from self-censure of their own actions and thus increase transgressive behavior. This is most likely to occur when retaliative counterreactions are self-justified as rectifying past grievances or preventing further maltreatment. Otherwise considerate people can thus be readily provoked by observed injustice to behave cruelly without remorse.

None of the foregoing explanations assurnes that vicarious reinforcement produces its effects by strengthening connections between stimuli and responses. Such a mechanism of operation would require observers, not only to perform covert matching responses concurrently with the model, but to experience indirectly the reinforcements. A reinforcement process of this type is not implausible, though it seems highly improbable.

Although the preceding discussion is concemed with possible mechanisms through which vicarious reinforcement affects observers, the alternative explanations apply equally to interpretation of how direct reinforcement influences performers. Reinforcements convey information to performers about the types of responses that are appropriate; selective reinforcement directs performers' attention to correlated environmental stimuli that signify probable response consequences; previous reinforcements create expectations that motivate actions designed to secure desired rewards and to avoid injurious outcomes; punishing experiences can endow persons, places, and things with fear-arousing properties that inhibit responsiveness; a given history of positive or negative reinforcement can alter people's self-evaluations in ways that affect their willingness to exhibit behaviors that are discrepant with their self-attitudes and the determination with which they perform them; and finally, the treatment one receives alters liking and respect for the reinforcing agent.

\section{Self-Reinforcement}

The discussion thus far has illustrated how people regulate their behavior on the basis of response consequences that they either observe or experience firsthand. If actions were determined solely by external rewards and punishments, people would behave like weathervanes, constantly shifting in radically different directions to conform to the whims of others. They would act like segregationists with a racial bigot, like John Birchers with a zealous Bircher, like Communists with a devoted Communist, like Republicans with a staunch conservative, and like scoundrels with a villainous character. Close scrutiny of social interactions would most likely reveal, barring powerful coercive pressures, steadfast adherence to ideological positions rather than compliant behavior reversals. Anyone who attempted to change a Bircher into a Communist, or a Catholic into an atheist, would quickly come to appreciate the existence of potent internal sources of behavior control.

The notion that behavior is controlled by its consequences is unfortunately interpreted by most people to mean that actions are at the mercy of situational influences. In fact, behavior can, and is, exten- 


\section{Albert Bandura}

sively self-regulated by self-produced consequences for one's own actions. In writing a term paper or preparing a manuscript for publication, for example, authors do not require someone sitting at their sides differentially reinforcing each written statement until a satisfactory version is produced. Rather, authors possess a standard of what constitutes an acceptable work and they engage in repeated self-corrective editing of their own writing performances until they are satisfied with what they have written. The selfediting often exceeds external requirements of what would be satisfactory to others. Indeed, some people are such severe self-editors that they essentially paralyze their own writing efforts. In most other areas of functioning people similarly set themselves certain performance standards and respond to their own behavior in self-satisfied or self-critical ways in accordance with their self-imposed demands. Because of their greater representational and self-reactive capacities, humans are less dependent upon immediate external supports for their behavior. The inclusion of self-reinforcement phenomena in learning theory thus greatly increases the explanatory power of reinforcement principles as applied to human functioning.

After a self-monitoring reinforcement system has been developed, a given action typically produces two sets of consequences-a self-evaluative reaction and an external outcome. These two sources of reinforcement can occur in several different patterns. Sometimes people are rewarded socially or materially for behavior that they devalue. Anticipation of self-reproach for personally repudiated actions provides an important motivating influence to keep behavior in line with adopted standards in the face of opposing influences. There is no more devastating punishment than self-contempt. Under conditions where self-devaluative consequences outweigh the force of rewards for accommodating behavior, external influences prove relatively ineffective. On the other hand, when external inducements, whether rewarding or coercive, prevail over self-reinforcing influences, individuals exhibit cheerless compliance. Humans, of course, are equipped with facile cognitive capacities for reconciling distressing discrepancies. Disliked actions can be, and often are, justified so that losses in self-respect are minimized as long as the self-deception remains convincing.

An opposite type of conflict between external and self-produced consequences arises when people are punished for engaging in activities they value highly. Here, the relative strength of self-approval and external censure determine whether the behavior will be discarded or maintained. Another common situation is one where external reinforcement for certain activities is minimal or lacking and individuals sustain their efforts largely through self-encouragement. External reinforcement exerts greatest influence when it is harmonious with, rather than contravenes, selfproduced consequences. People strive actively to achieve and to maintain such conditions. They do this by selectively associating with persons who share similar behavioral standards, thus ensuring social support-for their own system of self-evaluation.

There are three major aspects of self-reinforcement that warrant detailed comment. These issues are concerned with questions of how self-monitoring reinforcement systems are established; how effective they are in regulating behavior; and what maintains them.

\section{Establishment of Self-Reinforcing Functions}

Self-reinforcement functions can be acquired in several different ways. One of these is through the process of selective reinforcement. People learn to evaluate their behavior partly on the basis of how others have reacted to it. Parents and other socialization agents subscribe to certain norms of what constitute worthy performances. They are generally delighted and respond approvingly when children achieve or exceed desired standards and displeased when their performances fall short of the valued level. As a result of such differential treatment chil. dren eventually come to respond to their own behav. ior in self-approving and self-critical ways, depending on how it departs from evaluative standards set by others. Some indirect support for the effects of direct training on self-reinforcement practices is provided by Kanfer and Marston [1963]. They found that adults who had received indulgent treatment subsequently rewarded their performances more generously than did those who had been stringently trained, even though the actual achievements of both groups were comparable.

People not only prescribe self-evaluative standards for others, they also exemplify them in response to their own behavior. It is amply documented in psychological research that modeling is another influential means of transmitting systerns of self-reinforcement. In the procedure typically used to study this process, children or adults observe a model performing a task in which he adopts either a high or a low performance standard for self-reinforcement. On trials in which the model achieves or exceeds his self-imposed demand, he rewards himself tangibly and voices self-praise; but when his attainments fall short of self-prescribed requirements, he denies him- 


\section{Social Leaming Theory}

self freely available rewards and reacts in a selfderogatory manner. Observers later perform the task alone, receiving a predetermined set of scores. The performances for which they reward and punish themselves are recorded.

Results of such experiments show that people tend to adopt standards of self-reinforcement displayed by exemplary models, they evaluate their own performances relative to that standard, and then' they serve as their own reinforcing agents. In a study by Bandura and Kupers [1964] children who observed a model set a high standard of self-reinforcement later rewarded themselves sparingly and only when they achieved superior performances, whereas children exposed to models who considered low achievements deserving of self-reward tended to reinforce themselves for mediocre performances. A control group of children, who had no exposure to models, did not reward themselves selectively for differential levels of achievement. Subjects in the experimental conditions not only adopted the modeled standards of self-reinforcement but matched variations in the generosity with which the models rewarded their own performances.

Social groups contain members of widely differing abilities, so that a given individual must select the modeled standards against which to evaluate his own accomplishments. His level of self-satisfaction and of self-disappointment will be determined to a large extent by the models with whom he compares himself. A study by Bandura and Whalen [1966] found that children readily adopted self-reinforcement patterns displayed by either low-achieving models who were satisfied with mediocre performances or moderately competent models subscribing to self-reward standards within their reach. According to social comparison theory, people tend to choose reference models similar in ability and to disregard those who are too divergent from themselves. Consistent with this view, children rejected lofty standards of superior models and adopted lower self-reward requirements within the range of their achievements.

Although there is an understandable reluctance to emulate exacting norms of distinguished models, it is nevertheless not uncommon for people to adopt stringent standards of self-reinforcement. Indeed, universities are heavily populated with students who are self-satisfied only with superior performances in whatever academic work they undertake. We conducted an experiment in our laboratory to explore some of the social conditions that might lead people to emulate austere standards of self-reinforcement even though adherence to such demands results in frequent self-dissatisfaction [Bandura, Grusec, $\varepsilon$ Menlove 1967].

Children observed a highly capable adult who re warded himself only when he obtained superio: scores that children rarely achieved when they lates performed the same task. Prior to this experience the adult model treated half the children in a warm rewarding manner and the others in a neutral, businesslike fashion. The quality of the social relation ship was varied on the assumption that the reward ingness of a model, which tends to increase interper sonal attraction, would facilitate emulation of the model's exacting norms.

Adherence to high performance standards is gen erally publicly acclaimed. Without societal valuatior most people would forego lofty aspirations if only because their attainment requires arduous work anc much self-denial of readily available gratifications To measure the effects of observed social rewards with half the children in the experiment the adul: model was praised for adhering to stringent stand ards of self-reinforcement, but with the remaining children the model received no social recognition fo: his high-standard-setting behavior.

Ordinarily, individuals are exposed to a variety o: modeling influences, many of which operate in op posing directions. Speculations about the influencr of multiple modeling on social leaming generally assign importance to conflicting identification with adult and peer models. To study how children re solve the problem of simultaneous exposure to antag onistic modeling influences, half the children in each subgroup observed both the stringent adult and : peer model who displayed a low standard of self reward. When faced with a conflict between adul and peer standards, children would be predisposec toward peer modeling. Not only would a peer be viewed as a more appropriate comparison model bu emulation of high aspirations results in frequent self criticism of one's performances, which discourage: adoption of such standards. It was assumed, how ever, that the tendency for peer modeling to reducc the impact of adult modeling might be counteractec by opposing influences arising from positive ties to the adult model and from social recognition of high standard-setting behavior.

Children exposed to conflicting modeling influ ences were more inclined to reward themselves fo: low achievements than children who had observec only the adult model consistently adhering to a hig\} standard of self-reinforcement. Children were alsi more likely to impose severe criteria of self-rewarc on themselves when the adult model received socia 


\section{Albert Bandura}

recognition for his high-standard-setting behavior than when the model's stringent achievement demands went unrecognized. However, contrary to expectation, children who had experienced a highly nurturant interaction with the adult model were more likely to accept the low performance standard set by the peer than if the adult was less beneficent. A nurturant relationship was apparently interpreted by the children as permissiveness for lenient selfdemands.

Comparison of subgroups receiving various combinations of treatments revealed that the influence of the peer's liberal self-reward was effectively negated by praising the adult's high-standard-setting behavior. The most austere pattern of self-reinforcement was displayed by children who experienced a relatively nonnurturant relationship with the adult model, who had no exposure to conflicting peer norms, and who witnessed the adult receive social recognition for holding to high standards. These children, who rarely considered performances that fell below the adult's criterion worthy of self-reward, displayed unyielding self-denial. The adoption and continued adherence to unrealistically high selfevaluative standards is especially striking considering that the self-imposition of rigorous performance demands occurred under conditions where the children were at liberty to reward themselves whenever they wished without anyone around to judge their actions. Moreover, since children rarely attained the modeled standard, adopting it as an index of personal merit resulted in repeated self-devaluation and self-forbiddance of freely available rewards.

In everyday life it is not uncommon for people to differ in what they practice and in what they preach. Some parents, for example, lead a frugal self-denying life but are lenient in what they demand of their children; others are self-indulgent while expecting their children to subscribe to high standards of achievement entailing long hours of work and sacrifice of many day-to-day pleasures. A number of researchers have investigated the effects of such discrepancies on the development of self-reinforcement patterns [McMains \& Liebert 1968, Mischel \& Liebert 1966, Rosenhan, Frederick, \& Burrowes 1968]. The findings generally show that children reward themselves most sparingly when stringent standards have been consistently modeled and imposed, whereas social learning conditions in which adults both model and impose lenient performance demands produce children who reward themselves generously for mediocre attainments. Discrepant practices, on the other hand, in which models prescribe stringent standards for others but impose lenient ones upon themselves, or impose austere demands on themselves and lenient ones on others, reduce the likelihood that high standards of self-reward will be adopted.

The manner in which self-reward patterns may be passed on through a succession of models has been demonstrated by Mischel and Liebert [1966]. Children who had adopted high standards of self-reinforcement displayed by adults later modeled and applied the same standards in relation to peers. Marston [1965a] has likewise shown in an experiment with adults that seeing models reinforce their performances either generously or sparingly not only affected how liberally observers rewarded their own behavior but influenced the frequency with which they later reinforced another person performing the same task.

The laboratory findings corroborate field studies demonstrating that in cultures where austerity is consistently modeled and taught as the dominant social norm people not only reward themselves sparingly, but because of the emphasis on personal re sponsibility for high standards of conduct, self-denying, self-punitive, and depressive reactions are prevalent [Eaton \& Weil 1955]. By contrast, in societies where liberal self-gratification patterns predominate, people usually reward themselves generously for minimal performances [Hughes, Tremblay, Rapoport, \& Leighton 1960]

\section{Self-Reinforcement and Self-Concept}

Accounts of personality theories frequently draw sharp distiuctions between phenomenological approaches in which the self-concept is a central feature and behavioral orientations that supposedly dismiss self-evaluative phenomena. Behavior thepries differ among themselves, of course, in what they choose to study and in what they regard as the nature and locus of the causes of human behavior. It is evident from the preceding discussion that selfevaluative and self-reinforcing functions assume a prominent role in social leaming theory. It will be recalled that individuals who had been exposed to models favoring lenient standards of self-reinforcement were highly self-rewarding and self-approving for comparatively mediocre performances; conversely, persons who observed models adhering to stringent performance demands displayed self-denial and self-dissatisfaction for objectively identical accomplishments. These contrasting self-reactions to one's own behavior illustrate how self-esteem, self-concept, and related self-evaluative processes can be con- 
ceptualized within a social leaming framework. From this perspective, self-esteem is the result of discrepancies between a person's behavior and the standards that he has selected as indices of personal merit. When behavior falls short of one's evaluative standards, the person judges himself negatively or holds himself in low self-esteem. On the other hand, when performances coincide with, or exceed, a person's standards he evaluates himself favorably, which is considered indicative of high self-esteem.

The self-concept also reflects the phenomenon of self-reinforcement. Self-concept usually signifies a person's tendency to regard different aspects of his behavior positively or negatively. In measuring this personality characteristic individuals are presented with a set of evaluative statements in the form of adjective check lists, Q-sorts, or inventories and are asked to rate which statements apply to them. The individual responses are then summed to provide a global index of self-evaluation, which represents his self-concept. Within a social learning approach, a negative self-concept is defined in terms of frequent negative self-reinforcement of one's behavior; conversely, a favorable self-concept is reflected in a disposition to engage in high positive self-reinforcement. Marston [1965b] has conceptualized the phenomena subsumed under the term self-concept in much the same way.

Personality theories often attribute variations in behavior to differences in values. Behavioral approaches treat values largely in terms of incentive preferences. As we have already observed, the kinds of responses a person makes are affected by the positive and negative outcomes they are likely to produce. Traditional value theory; however, is more concerned with valuation of behavior than of external outcomes. Established personality theories tend to regard values as global personal entities that influence behavior but they fail to explain exactly how values control specific actions. Within the social learning framework, self-reinforcement is the control mechanism. The behavioral standards represent the values and the anticipatory self-satisfaction and self-criticism for actions that correspond to or deviate from the adopted standards serve as the controlling influences.

Dysfunctions in self-reinforcement systems often assume major importance in psychopathology through their capacity to create excessive self-punishment and aversive conditions that can maintain deleterious forms of deviant behavior. Many of the people who seek psychotherapy are behaviorally competent and free of debilitating anxiety, but they experience a great deal of personal distress stemming from excessively high standards of self-evaluation often supported by unfavorable comparisons with models noted for their extraordinary achievernents. As an unidentified pundit once remarked, "If you compare yourself with others, you may become vain or bitter; for always there will be greater and lesser persons than oneself." Yet social comparisons are inevitable, especially in societies that place a high premium on competitiveness and individual achievement. Ironically, talented individuals who have high aspirations that are possible but difficult to realize are especially vulnerable to self-dissatisfaction despite their notable achievements. As Boyd [1969] graphically describes this phenomenon, "Each violinist in any second chair started out as a prodigy in velvet knickers who expected one day to solo exquisitely amid towers Hung by dazzled devotees. The 45-year-old violinist with spectacles on his nose and a bald spot in the middle of his hair is the most disappointed man on earth." Linus, the security-blanketed member of the Peanuts clan, also alluded to this phenomenon when he wisely observed, "There is no heavier burden than a great potential."

In its more extreme forms, a harsh system of selfreinforcement gives rise to depressive reactions, chronic discouragement, feelings of worthlessness, and lack of purposefulness. Excessive self-disparagement, in fact, is one of the defining characteristics of psychotic depression. As Loeb, Beck, Diggory, and Tuthill [1967] have shown, depressed adults evaluate their performances as significantly poorer than do nondepressed subjects, even though their actual achievements are the same. People also suffer from considerable self-devaluation when they experience a loss in ability due to age or physical injury but continue to adhere to their original standards of achievement. In the latter instances, most of their performances are negatively self-reinforced to the point where they eventually become apathetic and abandon activities that previously brought them a great deal of personal satisfaction.

When a person's behavior produces self-punishing consequences; any activities that avert or reduce these disturbing effects are thereby strengthened and maintained. A variety of deviant behaviors can serve as means of escaping or avoiding self-generated distress. Some people whose accomplishments bring them a sense of failure resort to alcoholic selfanesthetization; others escape into grandiose ideation where they achieve in fantasy what they failed in reality; others protect themselves against self-condemnation for their lack of advancement by devel- 


\section{Albert Bandura}

oping delusions of persecution; still others are tragically driven by relentless self-disparagement to suicide; and many renounce pursuits that have selfevaluative implications and gravitate to social groups that embrace an antiachievement norm.

The preceding discussion portrays the personal misery that can result from stringent self-reinforcement. Social problems also arise from deficient or deviant self-reinforcement systems. Individuals who have failed to develop well-defined standards necessary for adequate self-regulating reinforcement and those who make self-reward contingent upon skillful performance of antisocial behavior readily engage in transgressive activities unless deterred by externally imposed controls. Similarly, individuals who set low behavioral standards for themselves are inclined to upset others by their indifference to achievement requirements.

\section{Behavior-Regulating Function of Self-Produced Consequences}

Psychologists have examined not only how people learn to respond to their own actions in self-rewarding and self-punishing ways but the degree to which they can control their own behavior by self-produced consequences. Bandura and Perloff [1967] compared the relative effectiveness of self-monitored and externally applied systems of reinforcement in an experiment that proceeded as follows: children worked at a manual task in which they could achieve progressively higher scores by performing increasingly more effortful responses. Eight complete rotations of a wheel were required to advance 5 points, so that, for example, a total of 16 cranking responses was required to achieve a score of 10,24 responses to attain a score of 15 , and a total of 32 cranking responses to rach the maximum score of 20 . Children in the selfreinforcement condition selected which of these achievement levels they would strive for and rewarded themselves whenever they attained their selfprescribed standard of performance. Children who performed under externally administered reinforcement were individually matched with members in the self-reward group so that the same achievement standard was externally set for them and the rewards were automatically delivered whenever they reached the predetermined level. To determine whether subjects' behavioral productivity was due to response reinforcement or to gratitude for the rewards that were made available, children in an incentive control group performed the task after they had received the rewards without any strings attached. A fourth group worked without any rewards at all to estimate the number of responses children would perform solely through interest in the task itself. Because the capacity to maintain effortful behavior is one of the most important features of a reinforcement operation, the dependent measure was the number of cranking responses the children performed until they no longer wished to continue the activity.

Children whose behavior was positively reinforced either by themselves or by others performed substantially more responses than children who received the rewards in advance or were never rewarded. Girls were equally productive under externally and selfadministered reinforcement. Although boys also worked hard when they rewarded their own performances, they were even more responsive under conditions where reinforcement was extemally regu-
lated.

Of special interest is the prevalence with which children in the self-monitored condition willingly imposed upon themselves highly unfavorable sched. ules of reinforcement. Not a single child chose the lowest score, which required the least effort, while approximately half of them selected the highest achievement level as the minimal performance meriting self-reward. Moreover, a third of the children later raised their initial standard to a higher level, without a commensurate increase in amount of selfreward, thereby requiring of themselves more work for the same recompense.

Why did children work themselves so hard when no one required them to do so? Since the experiment was not designed to provide evidence on this point, we can only speculate. It can be reasonably assumed that most older children have adopted standards of achievement through modeling and the evaluative reactions of others. Moreover, they are likely to have been criticized on many occasions for being selfsatisfied with performances judged to be unworthy. Hence, under conditions where persons are provided with opportunities to optimize their material outcomes by resorting to behavior that has low selfregard value, conflicting tendencies are aroused. On the one hand, they are tempted to maximize rewards at minimum effort costs to themselves; they can achieve this by simply lowering their performance standards. On the other hand, reward for low-quality performances evokes self-reproof, which, if suffciently strong, may inhibit undeserving self-compensation. Apparently, children were willing to deny themselves rewards over which they had full control rather than risk self-disapproval for unmerited selfreward. Many of the children, in fact, set themselves 


\section{Social Learning Theory}

performance requirements that incurred high effort costs at minimum material recompense. These findings are at variance with what one might expect on the basis of reward-cost theories, unless such formu. lations include the self-esteem costs of rewarding devalued behavior.

In recent years psychologists have been developing self-reinforcement procedures that would enable people to control their own behavior more effectively. These methods are applied most extensively to the modification of behaviors that are personally disturbing or that create chronic difficulties for others. Given clearly defined objectives and some practice on how valued rewards can be self-administered contingently, children are able to manage their aggressive and scholastic behavior as well as or better than their teachers through self-reinforcement practices [Goodlet \& Goodlet 1969, Glynn 1970, Lovitt \& Curtis 1969]. Self-administered aversive consequences have been used with some degree of success to reduce stuttering, obsessional ruminations, craving for addictive drugs, and deviant sexual behavior [Bandura 1969a].

Recent investigations of techniques of self-control also assign a principal role to self-managed reinforcement [Ferster, Nurnberger, \& Levitt 1962, Harris 1969, Stuart 1967]. In such treatment programs changes in highly refractory behavior are induced by having people regulate the stimuli that ordinarily control undesired and competing response patterns. However, unless positive consequences for self-controlling behavior are also arranged, the well-intentioned practices are usually short-lived.

Self-controlling behavior is difficult to maintain because it tends to be associated, at least initially, with relatively unfavorable conditions of reinforcement. Prepotent activities such as heavy drinking by alcoholics and excessive eating by obese people are immediately rewarding, whereas their detrimental consequences are not experienced for some time. Conversely, self-control measures usually produce immediate unpleasant effects while the personal benefits are considerably delayed. Self-reinforcement practices are, therefore, employed to provide immediate support for self-controlling behavior until the benefits that eventually accrue take over the reinforcing function. This is achieved by having individuals select a variety of activities that they find rewarding and make them contingent upon the performance of desired behavior.

The preceding studies primarily involve self-administration of tangible reinforcers. Of considerable interest is evidence that imagined consequences can serve a reinforcing function in regulating overt behavior. Weiner [1965] reports an experiment in which inappropriate motor responses by adults were either punished by withdrawal of monetary points or by having the subjects imagine the same loss of monetary points, or their performances had no consequences. He found that imagined aversive consequences and the actual occurrence of the same negative outcomes both reduced responding compared to the condition involving no feedback. Covert self-punishment, however, produced somewhat weaker reductive effects.

Although experimental demonstrations are lacking, there is every reason to expect that people can increase desired behavior by covert self-reward. The operation of covert self-reinforcement complicates interpretation of behavior changes accompanying external reinforcements. It may not be the lights, the scores, and the evaluative statements used as rewards in psychological experiments that are reinforcing; rather, such extrinsic events serve as cues that elicit covert self-satisfaction or self-criticism in subjects. It would follow from this line of reasoning that correctness feedback on tasks that are personally devalued or regarded as trifling is unlikely to activate self-reward and hence will not operate as a positive reinforcement. On the other hand, behavioral improvements are possible in the absence of extrinsic rewards because people can easily supply them to themselves. Preliminary findings of studies of selfreinforcement processes suggest that leaming approaches hold considerable promise for increasing people's capacity to regulate their own feelings, thoughts, and actions.

\section{Conditions Supporting \\ Self-Reinforcement Systems}

Since self-reinforcement systems are developed through social influence, there is no reason to assume that, once established, they become autonomous regulators completely impervious to subsequent social influences. An interesting, but inadequately explored, question is what supports self-reinforcing actions. No elaborate theory is needed to explain why people reward themselves. The challenging question requiring explanation is why people deny themselves available rewards over which they have full control, why they adhere to exacting standards that require difficult performances, and why they punish themselves. Several different interpretations have been proposed.

Conditioned relief. In the view advanced by Aronfreed [1964], people punish themselves because 


\section{Albert Bandura}

such responses have become endowed with anxiety relief value through prior conditioning experiences. This classical conditioning interpretation assumes that when parents discipline their children they often voice their criticism as they cease punishing them. If verbal criticism is repeatedly associated with the termination of punishment, criticism eventually becomes a relief signal indicating that punishment will soon end, thus allaying anxiety. Thereafter, when transgressive behavior arouses anticipatory fear, people criticize themselves for its conditioned tranquilizing effects. Self-critical responses persist, according to Aronfreed, because they are automatically reinforced by anxiety reduction.

To test this theory, Aronfreed conducted an experiment in which children performed an ambiguous task; on periodic occasions a buzzer sounded indicating that they had erred, at which point they were reprimanded for behaving the "blue" way and deprived of some candy. For one group the critical label "blue" was uttered as the buzzer and punishment were terminated; for a second group the label coincided with the onset of the buzzer and punishment; while with control children the blue label was verbalized as the buzzer was tumed off without any accompanying punishment. On subsequent trials, during which the buzzer signaled a transgression, children who experienced labeling at the termination of punishment were more inclined to verbalize the critical label than either the controls or children receiving labeling at onset of punishment, who did not differ from each other.

These findings are consistent with a conditioned reinforcement view, but other aspects of the data cast doubt on this interpretation. After transgressing, the children rarely uttered the critical label on their own and did so only after the punisher prompied it srom them through a series of questions concerning their actions. Given anxiety arousal, one would expect an anxiety reducer to be performed quickly and spontaneously. Why endure discomfort if one can promptly relieve it by a soothing self-critical word? The children's initial reluctance but later differential use of the critical label can be more adequately explained in terms of its assumed functional value rather than its conditioned tranquilizing properties. Children for whom the critical label brought on punishment would have little reason to use it. On the other hand, those who had earlier observed that the critical verbalization terminated punishment would be inclined to try it as a defensive maneuver in the face of the punisher's probing. Once having seen that uttering the critical word apparently eliminated at least the punisher's verbal reprimand, children would tend to repeat it for its presumed instrumental value. Moreover, when children did use the blue label on signaled errors, it remains unclear whether they were simply reporting that they performed the "blue" way or whether they were in fact voicing self-criticism. An adequate test of the conditioning view of selfcriticism, therefore, requires a situation in which children are provided with opportunities to actually criticize their actions in the absence of the punisher, thereby removing any possible external gains for such behavior. It might be noted in passing that the conditioning theory would also require several complicated assumptions to explain how people adopt self-punishing responses by observing punishments self-administered by a model for devalued behavior without observers receiving any direct painful treatment.

Reduction of self-generated distress. When a person performs inadequately or violates his own standards of conduct, he is likely to experience selfdeprecatory and other types of distressing thoughts. During the course of socialization the sequence of transgression-internal distress-punishment-relief is repeatedly experienced. In this process performance of punishable behavior creates anticipatory fears that often persist in varying degrees until the person is reprimanded. Punishment not only terminates worries over discovery of the transgression and possible social condemnation, but it also tends to restore the favor of others. Thus, punishment can provide relief from thought-produced anguish that is enduring and often more painful than the actual reprimand itself. This phenomenon is most vividly illustrated in extreme cases where people torment themselves for years over relatively minor transgressions and do not achieve equanimity until after making reparations of some type. Self-punishment may serve a similar distress-relief function. Having criticized or punished themselves for undesirable actions, individuals are likely to discontinue further upsetting ruminations about their behavior.

The way in which self-punishment can be maintained by averting anticipated threats is strikingly demonstrated by Sandler and Quagliano [1964]. After monkeys learned to press a lever to avoid being shocked, a second contingency involving self-administered punishment was introduced. A lever press prevented the occurrence of the original shock, but it also produced an electric shock of lesser magnitude. As the experiment progressed, the self-administered shock was gradually increased in intensity until it equaled the one being avoided. However, the 
animals showed no reduction in self-punishment even though this behavior no longer served as a "lesser of two evils." Even more interesting, after the avoided shock was permanently discontinued but lever-pressing responses (which had now become objectively functionless) still produced painful consequences, the animals continued to punish themselves needlessly with shock intensities that they had previously worked hard to avoid. This experiment reveals how self-punishment can become autonomous of contemporaneous conditions of reinforcement and be maintained through its capacity to forestall imagined threats that no longer exist.

In psychotic disorders, self-punishment is often powerfully maintained by delusional contingencies that have little relationship to reality. In a case to be cited later, a man who judged trivial acts as heinous sins could relieve his fright of hellish torment and feelings of self-contempt only by performing exceedingly self-punitive behaviors for long hours.

The preceding analysis of self-punishment can be applied as well to self-disappointing performances as to moral conduct. Like transgressive behavior, inferior performances can be a source of disconcerting thoughts and social disapproval that individuals will strive to reduce by criticizing or punishing themselves.

External reinforcement. Although self-punishment can be reinforced by its capacity to end or at least to reduce thought-produced distress, self-reinforcing responses are partly sustained by periodic external reinforcement. Adherence to high standards of selfreinforcement is actively supported through a vast societal system of rewards involving praise, social recognition, and a variety of awards and honors, whereas few accolades are bestowed on people for rewarding themselves on the basis of mediocre performances. To the extent that people choose a reference group whose members share similar behavioral norms for self-reinforcement, a given individual's self-evaluations are undoubtedly influenced by the actual or anticipated reactions of members whose judgments he values. When a person's immediate reference group is small and select, his self-evaluations are not much influenced by the views of others, and he sometimes appears to be an "inner-directed" person [Riesman 1950], although, in fact, he is highly responsive to a few individuals whose good opinion he prizes. The man is rare who regards his behavior so highly that the reactions of his fellows have no effect on his self-evaluation.

In everyday life high evaluative standards are not only favored, but negative sanctions are frequently applied to discourage inappropriate positive selfreinforcement. Rewarding oneself for inadequate or undeserving performances is more likely than not to evoke critical reactions from others. Similarly, lowering one's performance standards is rarely considered praiseworthy.

Self-punishment often serves as an effective means of lessening negative reactions from others. When misdeeds are almost certain to evoke disciplinary actions, self-punishment may be the lesser of two evils. Stone and Hokanson [1969] show how selfpunitive behavior can be effectively maintained by its self-protective and emotion-reducing function. When adults could avoid painful shocks by administering to themselves shocks of lesser intensity, selfpunitive responses not only increased but were accompanied by reduction in autonomic arousal.

Finally, verbal self-punishment can be a good way of extracting commendations from others as well. By criticizing and belittling themselves, people can predictably get others to enumerate their noteworthy accomplishments and abilities, and to issue reassuring predictions that continued effort will produce future triumphs. In summary, self-reinforcing behavior is intermittently reinforced by both subjectively created contingencies and various external sources.

\section{Cognitive Control}

If human behavior could be fully explained in terms of external stimulus conditions and response consequences, there would be no need to postulate any additional regulatory mechanisms: Actions are not always predictable from these external sources of influence, however, because cognitive factors partly determine what one observes, feels, and does at any given moment. In the present discussion, cognitive events refer to imagen; , to representations of activities in verbal and other simbols, and to thought processes. There are several ways in which cognitive functioning enters into the regulation of human behavior. These are discussed next.

\section{Cognitive Representation of Reinforcement Contingencies}

It was previously shown that repeated paired stimulation generally fails to produce conditioned responses as long as the connection between stimulus events goes unnoticed. Response consequences similarly have little or no effect on behavior when the relationship between one's actions and outcomes is 


\section{Albert Bandura}

not recognized. On the other hand, cognitive representation of conditions of reinforcement typically results in abrupt improvements in performance, indicative of insightful functioning.

Another interesting way of analyzing the process of cognitive control is to pit the power of belief against experienced reinforcement in the regulation of behavior. Several researchers have systematically explored the degree to which cognitive influences attenuate, distort, or nullify the effects of response consequences. Kaufman, Baron, and Kopp [1966] conducted a study in which motor responses of adults were rewarded each minute on the average (variable-interval schedule). One group was correctly informed about how often their performances would be rewarded, whereas other groups were misled into believing that their behavior would be reinforced either every minute (fixed-interval schedule) or after they had performed 150 responses on the average (variable-ratio schedule). Beliefs about the prevailing conditions of reinforcement outweighed the influence of experience consequences. Although all subjects actually received the same pattern of reinforcement, those who thought they were being rewarded once every minute produced very low rates of response (mean $=6)$; those who thought they were reinforced on a variable-ratio schedule maintained an exceedingly high output $($ mean $=259)$; while those who were correctly informed that their behavior would be rewarded on the average every minute displayed an intermediate level of responsiveness ( mean $=65$ ).

Human behavior is regulated to a large extent by anticipated consequences of prospective actions. Individuals may accurately assess the customary effects of given activities but fail to act in accordance with existing conditions of reinforcement because of false hope that their actions may eventually produce favorable outcomes. In one study some children persisted in imitating nonfunctional responses of a model that were never reinforced in the erroneous belief that their continued imitativeness might change his reinforcement practices [Bandura \& Barab 1971]. People also lead themselves astray by inaccurate expectations when they wrongly assume that certain changes in their behavior will alter future response consequences.

The oft-repeated dictum that behavior is controlled by its immediate consequences holds up better under close scrutiny for anticipated consequences than for those that actually impinge on the organism. In most instances customary outcomes are reasonably good predictors of behavior because the consequences that people anticipate for their actions are accurately derived from, and therefore correspond closely to, prevailing conditions of reinforcement. Belief and actuality, however, do not always coincide, because anticipated consequences are also partly inferred from observed response consequences of others, from what one reads or is told, and from a variety of other cues that, on the basis of past experiences, are considered reliable forecasters of likely outcomes. When actions are guided by anticipated consequences derived from predictors that do not accurately reflect existing contingencies of reinforcement, behavior is weakly controlled by its actual consequences until cumulative experiences produce more realistic expectations.

In some of the more severe behavior disorders, psychotic actions are so powerfully controlled by bizarre subjective contingencies that the behavior remains unaffected by its external consequences. This process is vividly illustrated in the passages quoted below [Bateson 1961], taken from a patient's account of his psychotic experiences in an insane asylum during the early $1800^{\circ}$ s. The narrator had received a scrupulously moralistic upbringing, according to which actions ordinarily viewed as fully acceptable were judged by him to be deviant, sinful, and likely to provoke the wrath of God; consequently, many innocuous acts elicited dreadful apprehensions, which in turn motivated and maintained exceedingly painful atonement rituals designed to forestall the imagined disastrous consequences.

In the night I awoke under the most dreadful impressions; I heard a voice addressing me, and I was made to imagine that my disobedience to the faith, in taking the medicine overnight, had not only offended the Lord, but had rendered the work of my salvation extremely difficult, by its effect upon my spirits and humours. I heard that I could only be saved now by being changed into a spiritual body. ... A spirit came upon me and prepared to guide me in my actions. I was lying on my back, and the spirit seemed to light on my pillow by my right ear, and to command my body. I was placed in a fatiguing attitude, resting on my feet, my knees drawn up and on my head, and made to swing my body from side to side without ceasing. In the meantime, I heard voices without and within me, and sounds as of the clanking of iron, and the breathing of great forge bellows, and the force of flames.... I was told, however, that my salvation depended on my maintaining that position as well as I could until the morning; and oh! great was my joy when I perceived the first brightness of the dawn, which I could scarcely believe had arrived so early
[pp. 28-29].

In the experiences described above, the anxiety instigators and the influential response consequences are both internally created. Acceptance of medicine, 


\section{Social Learning Theory}

an act later considered a rebellion against, and mistrust of, the Almighty, aroused dreadful hallucinations of Hadean torture, which could be banished only by performance of arduous bizarre behavior. The nonoccurrence of subjectively feared, but objectively nonexistent, threats undoubtedly serves as an important source of reinforcement, maintaining many other types of psychotic behavior. Given fictional contingencies with a powerful internal reinforcing system, a person's behavior is likely to remain under very poor environmental control even in the face of severe external punishments and blatant disconfirming experiences.

When I opened the door, I found a stout man servant on the landing, who told me that he was placed there to forbid my going out, by the orders of Dr. P. and my friend; on my remonstrating, he followed me into my room and stood before the door. I insisted on going out; he, on preventing me. I warned him of the danger he incurred in opposing the will of the Holy Spirit, I prayed him to let me pass, or otherwise an evil would befal him, for that I was a prophet of the Lord. He was not a whit shaken by my address, so, after again and again adjuring him, by the desire of the Spirit whose word I heard, I seized one of his arms, desiring it to wither; my words were idle, no effect followed, and I was ashamed and astonished.

Then, thought I, I have been made a fool of! But I did not on that account mistrust the doctrines by which I had been exposed to this error. The doctrines, thought I, are true; but I am mocked at by the Almighty for my disobedience to them, and at the same time, I have the guilt and the grief, of bringing discredit upon the truth, by my obedience to a spirit of mockery, or, by my disobedience to the Holy Spirit; for there were not wanting voices to suggest to me, that the reason why the miracle had failed, was, that I had not waited for the Spirit to guide my action when the word was spoken, and that I had seized the man's arm with the wrong hand [p. 33].

The voices informed me, that my conduct was owing to a spirit of mockery and blasphemy having possession of me .... that I must, in the power of the Holy Spirit, redeem myself, and rid myself of the spirits of blasphemy and mockery that had taken possession of me.

The way in which I was tempted to do this was by throwing myself on the top of my head backwards, and so resting on the top of my head and on my feet alone, to turn from one side to the other until I had broken my neck. I suppose by this time I was already in a state of feverish delirium, but my good sense and prudence still refused to undertake this strange action. I was then accused for faithlessness and cowardice, of fearing man more than God.

I attempted the command, the servant prevented me. I lay down contented to have proved myself willing to obey in spite of his presence, but now I was accused of not daring to wrestle with him unto blows. I again attempted what I was enjoined. The man seized me, I tore myself from him, telling him it was necessary for my salvation; he left me and went down stairs. I then tried to perform what I had begun; but now I found, either that I could not so jerk myself round on my head, or that my fear of breaking my neck was really too strong for my faith. In that case I then certainly mocked, for my efforts were not sincere.

Failing in my attempts, I was directed to expectorate violently, in order to get rid of my two formidable enemies; and then again I was told to drink water, and that the Almighty was satisfied; but that if I was not satisfied (neither could I be sincerely, for I knew I had not fulfilled his commands), I was to take up my position again; I did so; my attendant came up with an assistant and they forced me into a straight waistcoat. Even then I again tried to resume the position to which I was again challenged. They then tied my legs to the bed-posts, and so secured me [pp. 34-35].

Grotesque homicidal actions provide other striking illustrations of how behavior can come under bizarre symbolic control. A study of presidential assassins [Weisz \& Taylor 1970], for instance, shows that, with one exception, the murderous assaults were partly under delusional control. The assassins were driven to acts of violence by divine inner voices commanding them to do so, by delusional beliefs that the victim was conspiring to harm them, and by grandiose convictions that it was their heroic responsibility to eliminate maleficent leaders in positions of power. The assassins, being unusually seclusive in their behavior, shielded the delusional beliefs from corrective social influences.

\section{Representational Guidance of Behavior}

Symbolic processes play a prominent role in the acquisition and retention of response patterns as well as in their expression. The memory trace of monetary influences is short-lived, but such experiences often have lasting behavioral effects. This condition is made possible by the fact that transitory external events are coded and stored in symbolic form for memory representation. Patterns of behavior that have been observed and other experiences long past can thus be reinstated by visualizing them or by representing them verbally. These internal models of the outside world can serve as guides to overt action on later occasions. It will be recalled from the earlier discussion of learning processes that internal representations of patterned behavior are constructed from observed examples and from informative feedback to one's trial-and-error performances.

Representational mediators are especially influential in early phases of response acquisition. After ac- 


\section{Albert Bandura}

tion patterns have become routinized through overlearning, they are usually performed smoothly and automatically without requiring intermediary imaginal or verbal guidance. Skilled performance can, in fact, be disrupted by visualizing or thinking about what one must do next while carrying out the activity.

\section{Thought Control of Action through Covert Problem Solving}

Man's efforts to understand and to manage his environment would be exceedingly wearisome, and perilous as well, if optimal solutions to problems could be arrived at only by performing alternative actions and suffering the consequences. Fortunately. most problem solving occurs in thought rather than in action. Man's higher mental capacities, for example, enable him to design sturdy dwellings and bridges without having to build them until he hits upon a structure that does not collapse. Altemative courses of action are generally tested in symbolic exploration and either discarded or retained on the basis of calculated consequences. The best symbolic solution is then executed in action.

Symbols that represent external events, operations, and relationships are the vehicle of thought. Most thinking occurs in terms of language symbols. By manipulating words that convey relevant information, one can gain an understanding into causal processes, anrive at solutions, and deduce consequences. Thinking also occurs in numerical and other symbols. The functional value of thought depends upon close correspondence between the symbolic system and external events so that the latter can be substituted for the former. Thus, subtracting the number 2 from 10 yields the same outcome as physically performing 'he operation of removing two objects from a group of ten. Symbols can be manipulated much more easily than their physical counterparts, which greatly increases the scope and power of symbolic problem solving. Since symbols are the instruments of thought, the level of symbolization development partly determines reasoning capacities.

The process by which people leam to attain solutions covertly has received comparatively little attention, despite its focal role in human functioning. Being a private activity, of course, it is not readily accessible to empirical investigation. Such cognitive skills are usually developed by performing operations initially on actual objects and then gradually translating the external processes to covert symbolic ones of increasing complexity and abstraction. In the teaching of arithmetic principles, for instance, children first learn the formal operations of addition and subtraction by combining and withdrawing real ob- jects. Pictorial representations are also used in early phases as aids to acquiring arithmetic skills. After children have learned to solve arithmetic problems through physical manipulation of things, the objects are symbolized by numbers. Correct solutions are now achieved by manipulation of numerical symbols on paper, where each step can be checked and corrected. The process at this stage is still partially overt but the solutions are symbolic. Eventually the symbolic solutions are achieved covertly by having children think out the problem within their heads. Overt and covert operations do not differ in any fundamental way, although covert problem solving generally makes heavy demands on memory processes. For this reason various diagrammatical and mechanical aids are used when solutions to problems require complex chains of symbolic activities.

\section{Interaction of Controlling Influences}

The three major systems by which behavior is regulated do not operate independently. Most actions are simultaneously controlled by two or more of the component influences. Moreover, the various systems are closely interdependent in acquiring and retaining their power to determine behavior. In order to establish and to maintain effective stimulus control, for example, the same actions must produce different consequences, depending on the cues that are present. If walking through intersections on red or green signals left one equally vulnerable to being knocked down by automobiles, pedestrians would quickly disregard traffic lights and rely on other informative cues to guide them safely through busy thoroughfares. Earlier we noted how the effectiveness of verbal and other social influences is negated by faulty reinforcement practices and reinstated by ensuring that predictable consequences will ensue for responding in a particular way to certain stimulus situations.

The preceding comments illustrate how stimulus determinants of behavior can be markedly affected by how they are correlated with reinforcing consequences. Stimulus and cognitive influences, in tum, can alter the impact of prevailing conditions of reinforcement. Conditioned aversive stimuli can acquire such powerful control over defensive behavior that people avoid renewed encounters with feared persons or things. In instances where the original threats no longer exist, their self-protective behavior is insulated from realistic reinforcement control.

Even when the things one dislikes or fears are not completely avoided, stimuli having strong emotionarousing potential provoke defensive behaviors that predictably create adverse reinforcement contingen- 


\section{Social Learning Theory}

cies where they may not ordinarily exist. We'might draw again on the advice column of a newspaper counselor to illustrate this process.

\section{Dear Abby:}

I have trouble with blondes. Every time I go for a girl and she is a blonde she turns out to be a gold-digger. I notice on TV whenever they have a gold-digger she is blonde. The last blonde I went with asked me to buy a record every time I took her out. She kept me busted buying her records. Should I pass up all blondes from now on?

Dear Blonde Trouble:

Blonde Trouble

Plenty of golden heads have golden hearts.

Abby

To the extent that the correspondent's distrust of blondes leads him to behave in ways that provoke unfriendly counteractions from them, the negative valence of blonde hair is repeatedly strengthened, and it in turn prompts actions that produce reciprocal negative reinforcement. Both processes thus support each other.

The way in which beliefs and conscious recognition of environmental contingencies can enhance, distort, or even negate the influence of reinforcing consequences has already been amply documented and needs no further illustration. Cognitive events, however, do not function as autonomous causes of behavior. Their nature, their valence, and their occurrence are under stimulus and reinforcement control. Analysis of cognitive control of behavior is therefore incomplete without specifying what controls the influential cognitions.

Cognitively based conditioning, for example, cannot occur unless the thoughts that serve as sources of emotional responses have been endowed with arousal potenial. The research of Miller [1951] and Grose [1952] demonstrates that thoughts can acquire emotion-provoking properties through generalization from reinforcing experiences associated with overt responses. In these studies it was found that thoughts corresponding to verbalizations that had been punished generated physiological arousal, whereas thoughts representing nonpunished verbalizations elicited no emotional reactions. If the painful experiences are sufficiently intense, however, they can condition such potent aversive properties that the disturbing thoughts themselves are completely inhibited [Eriksen \& Kuethe 1956, Marks \& Gelder 1967]. In personality theories, thought inhibition is usually designated as repression.

Thoughts remain partly under external stimulus control. Thus, the thoughts elicited in a hospital are markedly different from those aroused in a discotheque. A simple cue from a past experience can reinstate reveries of bygione events. And perturbing trains of thought can be turned off by directing one's attention to absorbing matters that elicit superseding cognitive activities. This form of self-control, in which thought-produced arousal is diminished by engrossment in absorbing literary material, televised programs, vocational and avocational pursuits, and other engaging projects, is widely used to restore a sense of well-being.

The rules and principles that people use to guide their actions do not arise in a mental vacuum. When rules defining appropriate behavior in given situations are not explicitly designated, they are arrived at largely through information conveyed by observed or experienced response consequences. Provisional hypotheses that produce responses resulting in reinforcement are retained, partially correct hypotheses are successively refined on the basis of differential response feedback until the right one is hit upon, and hypotheses that give rise to faulty performances are promptly discarded. While it is true that implicit rules govern behavior, the rules themselves are partly fashioned out of reinforcement experiences.

Considering the intricate interdependence of stimulus, reinforcement, and cognitive control systems, the sharp distinctions frequently drawn between reinforcement and cognitive theories are of questionable value. It has been customary in psychological theorizing to construct entire explanatory schemes around a single form of behavioral control, to the relative neglect of other obviously influential determinants and processes. Some theories have tended to concentrate upon stimulus control effected principally through association of experiences; others have primarily focused upon extemal reinforcement control; and advocates favoring cognitive interpretations confine their interest largely to symbolic mediators. These resolute allegiances to part processes may encourage intensive investigation of subsystems, but considered alone, they do not provide a complete understanding of human behavior.

\section{Social Learning as a Reciprocal Influence Process}

In the social leaming view, psychological functioning involves a continuous reciprocal interaction between behavior and its controlling conditions. Early attempts to incorporate both individual and environmental determinants in personality theory simply depicted behavior as caused by these two sets of influences. In the widely cited equation $B=f(P, E)$, actions were presumably best understood by consider- 
ing the joint effects of personal attributes and environmental pressures. The major weakness of this type of formulation is that it treats response dispositions and the environment as independent entities. Contrary to this assumption, the environment is only a potentiality, not a fixed property that inevitably impinges upon individuals and to which their behavior eventually adapts. Behavior partly creates the environment and the resultant environment, in turn, influences the behavior. In this two-way causal process the environment is just as influenceable as the behavior it controls.

Illustrations of how behavioral disposition and the environment affect each other can be found even in simple experiments with animals. To study defensive reactions to threats, Sidman [1966] devised a situation in which animals could postpone the occurrence of painful shocks for a given period by depressing a lever. Shocks, for example, may be scheduled to occur every minute, but each bar press forestalls it for thirty seconds so that animals have an effective means for controlling the punitiveness of their environment. Under these conditions animals that quickly learn the adaptive behavior create for themselves an environment that is essentially free of punishment. Others who, for one reason or another are slow in acquiring the requisite coping responses experience a highly unpleasant milieu. Though the potential environment is identical for all animals, the actual environment varies in accordance with their behavior. Is the animal controlling the environment or is the environment controlling the animal? What we have here is a two-way control system, and it is arbitrary which aspect of it we choose to record. When changes in the animals' behavior are selected for analysis, the environmental contingencies appear to be the controllers of behavior. If, instead, one examines the amount of punishment created by each subject, it is the environment that is controlled and modified by the animals' actions, and it can therefore vary considerably for different subjects and at different times for the same subject. In examining how behavior determines the environment, one might, for instance, administer alcohol to one group and water to another within the same programmed milieu and then compare the types of aversive environments subjects create for themselves under intoxicated and under sober conditions.

The rewarding aspect of an environment is also only a potentiality until actualized through appropriate actions. A researcher once studied the behavior of schizophrenic and normal children in a room containing an extraordinary variety of reinforcing de- vices including, among other things, a pinball machine, a color wheel, a television set, a phonograph, an electric train, a picture viewer, an electric organ, and candy-and trinket-vending machines. To actuate these various playthings, children had simply to deposit available coins, but only when a light was turned on; coins deposited when the light was off extended the period that the device would remain inoperative. Normal children rapidly learned the requisite behavior and created an unsually beneficent environment for themselves. On the other hand, the schizophrenic children, who failed to master this simple skill, experienced the same potentially rewarding environment as a depriving and emotionally
disturbing place.

In the preceding examples, the features of the potential environment were highly restricted. Social environments, on the other hand, provide a much greater latitude for creating contingencies that can in turn affect one's own behavior. People can converse on a multiplicity of topics, they can do a variety of things, and in other ways their potential range of responsiveness is exceedingly broad. In a given social interaction the behaviors of the participants largely determine which aspects of their respective repertoires are actualized and which remain unexpressed. Some people bring out the best in others, while other individuals have a talent for bringing out the worst in those with whom they interact.

In examining sequential interchanges between children, Rausch [1965] found that the immediately preceding act of one person was the major determinant of the other person's response. In approximately 75 per cent of the instances, hostile behavior elicited unfriendly responses, whereas cordial antecedent acts seldom did. Aggressive children thus created through their actions a hostile environment, whereas children who displayed friendly interpersonal modes of response generated an amicable social milieu. With little effort we could readily identify problem-prone individuals with aversive styles of behavior that predictably produce negative social climates wherever they go. Far from being ruled by an imposed environment, people play an active role in constructing their own reinforcement contingencies through their characteristic modes of response.

It might be argued that if each person partly creates his own environment there is no one remaining to be influenced. This apparent paradox overlooks the fact that reciprocity is rarely perfect because one's behavior is not the sole determinant of subsequent events. Situational factors, the roles that 


\section{Social Learning Theory}

people occupy, and other considerations partly determine what one can or cannot do in response to the actions of others. Furthermore, controlling and counteracting influences usually occur in an alternating pattern, rather than concurrently, until each participant gets what he wants.

The operation of reciprocal reinforcement processes in the unwitting production of troublesome child behavior illustrates the point. On most occasions children's mild requests go unheeded because the parent is disinterested or preoccupied with other activities. If further bids also go unrewarded, the child will generally display progressively more intense behavior that becomes increasingly aversive to the parent. At this stage in the interaction sequence the child is exercising aversive control over the parent. Eventually the parent is forced to terminate the troublesome behavior by attending to the child, thereby reinforcing obstreperous responsiveness. Since the child gains parental attention and the parent gains temporary peace, the behavior of both participants is rewarded, although the long-term effects benefit neither. As shown in this example, detrimental reciprocal systems are often unknowingly created and mutually sustained when particular social practices evoke deviant behavior, which, due to "its aversive properties, creates the very conditions likely
to perpetuate it.

Interpersonal difficulties are most likely to arise when a person has developed a narrow range of effective behaviors and must thereby rely on coercive methods to force desired actions from others. Nag. ging complaints, aggressiveness, thinly veiled threats, helplessness, sick-role behavior, and emotional expressions of rejection, suffering, and distress are compelling means of controlling others, especially if the relationship involves some mutual dependence. The manner in which one treats conditions of this sort differs substantially, depending on whether such disturbances or viewed as by-products of intrapsychic influences or in terms of their functional value in reciprocal interactions are most effectively modifed by withdrawing the reinforcement supporting coercive behavior and by developing more constructive means of securing desired reactions from others.

Because social control involves a two-way process, it is exceedingly doubtful that the Brave New Worlds and the 1984s will ever be attainable, even as knowledge about the conditions governing human behavhave counter. Wherever you have controllers you experience some feeling as well. Both parties usually ing the outcomes they desire. Parents voice discouragement because they cannot get their children tollow their wishes, whereas children feel constrained by their parents from doing what they want. At universities the administrators, faculty, students, and alumni all feel that the other constituencies are unduly influential but that they themselves have insufficient power to alter the institutional practices. In government functioning Congress feels that the executive branch has excessive power, and conversely the executive branch feels thwarted in achieving its programs by congressional countercontrol. Whatever the levels of interaction might be, no one party is able to manipulate the other at will. Indeed, reciprocal influence systems are protected by legal and social codes designed to prevent easy use of imperious control with impunity. 


\section{BIBLIOGRAPHY}

Justin Aronfreed, "The Origin of Self-Criticism." Psychological Review, 1964, 71:193-218.

Teodoro Ayllon and E. Haughton, "Control of the Behavior of Schizophrenic Patients by Food." Journal of the Experimental Analysis of Behavior, 1962, 5:343352.

Teodoro Ayllon and Jack Michael, "The Psychiatric Nurse as a Behavioral Engineer." Joumal of the Experimental Analysis of Behavior, 1959, 2:323-334.

Donald M. Baer and James A. Sherman, "Reinforcement Control of Generalized Imitation in Young Children." Journal of Experimental Child Psychology, 1964, 1:37-
49 .

Albert Bandura, "Social Learning through Imitation." In Marshall R. Jones, ed., Nebraska Symposium on Motivation: 1962. University of Nebraska Press, 1962.

Albert Bandura, "Influence of Models' Reinforcement Contingencies on the Acquisition of Imitative Responses." Journal of Personality and Social Psychology $1965,1: 589-595$.

Albert Bandura, Principles of Behavior Modification. Holt, Rinehart \& Winston, 1969a.

Albert Bandura, "Social-Learning Theory of Identificatory Processes." In David A. Goslin, ed., Handbook of Socialization Theory and Research. Rand McNally, 1969b.

Albert Bandura, "Psychotherapy Based upon Modeling Principles." In Allen E. Bergin and Sol L. Garfield, eds., Handbook of Psychotherapy and Behavior Change.
Wiley, 1971a. Albert Bandura, ed., Psychological Modeling: Conflicting
Theories. Aldine Atherton, 1971b.

Albert Bandura, "Vicarious and Self-Reinforcement Processes." In Robert Glaser, ed., The Nature of Reinforcement. Merrill, 1971c.

Albert Bandura and Peter G. Barab, "Conditions Governing Nonreinforced Imitation." Developmental Psychology, 1971, in press.

Albert Bandura, Edward B. Blanchard, and Brunhilde Ritter, "The Relative Efficacy of Desensitization and Modeling Approaches for Inducing Behavioral, Affective, and Attitudinal Changes." Journal of Personality and Social Psychology, 1969, 13:173-199.

Albert Bandura, Joan E. Grusec, and Frances L. Menlove, "Observational Learning as a Function of Symbolization and Incentive Set." Child Development,
1966, 37:499-506.

Albert Bandura, Joan E. Grusec, and Frances L. Menlove, "Some Social Determinants of Self-Monitoring Reinforcement Systems." Journal of Personality and Social Psychology, 1967, 5:449-455.

Albert Bandura and Mary B. Harris, "Modification of Syntactic Style." Joumal of Experimental Child Psychology, 1966, 4:341-352.

Albert Bandura and Robert Jeffery, "Role of Symbolic Coding and Rehearsal Processes in Observational Learning." Unpublished manuscript, Stanford Univer-
sity, 1971.
Albert Bandura and Carol J. Kupers, "The Transmission of Patterns of Self-Reinforcement through Modeling." Journal of Abnomal and Social Psychology, 1964,
$69: 1-9$.

Albert Bandura and Frederick J. McDonald, "The Influence of Social Reinforcement and the Behavior of Models in Shaping Children's Moral Judgments." Journal of Abnomal and Social Psychology, 1963, $67: 274-281$.

Albert Bandura and Walter Mischel, "Modification of Self-Imposed Delay of Reward through Exposure to Live and Symbolic Models." Journal of Personality and Social Psychology, 1965, 2:698-705.

Albert Bandura and Bernard Perloff, "Relative Efticacy of Self-Monitored and Extemally-Imposed Reinforcement Systems." Journal of Personality and Social Psychology, 1967, 7:111-116.

Albert Bandura and Ted L. Rosenthal, "Vicarious Classical Conditioning as a Function of Arousal Level." Journal of Personality and Social Psychology, 1966, 3:54-

Albert Bandura, Dorothea Ross, and Sheila A. Ross, "Imitation of Film-Mediated Aggressive Models." Journal of Abnormal and Social Pyschology, 1963a, 66:3-11.

Albert Bandura, Dorothea Ross, and Sheila A. Ross, "A Comparative Test of the Status Envy, Social Power, and Secondary Reinforcement Theories of Identificatory Learning." Journal of Abnormal and Social Psy. chology, 1963b, 67:527-534.

Albert Bandura and Carol K. Whalen, "The Influence of Antecedent Reinforcement and Divergent Modeling Cues on Patterns of Self-Reward." Journal of Personality and Social Psychology, 1966, 3:373-382.

Theodore X. Barber and Karl W. Hahn, Jr., "Experimental Studies in 'Hypnotic' Behavior: Physiological and Subjective Effects of Imagined Pain." Journal of Nervous and Mental Disease, 1964, 139:416-425.

Gregory Bateson, ed., Perceval's Narrative: A Patient's Account of His Psychosis, 1830-1832. Stanford University Press, 1961

Alan A. Benton, "Effects of the Timing of Negative Response Consequences on the Observational Learning of Resistance to Temptation in Children." Dissertation Abstracts, 1967, 27:2153-2154.

Seymour M. Berger, "Incidental Learning Through Vicarious Reinforcement." Psychological Reports, 1961,
9:477-491.

Seymour M. Berger, "Conditioning through Vicarious Instigation." Psychological Review, 1962, 69:450-466.

Seymour M. Berger and Sandra L. Johansson, "Effect of a Model's Expressed Emotions on an Observer's Resistance to Extinction." Journal of Personality and Social Psychology, 1968, 10:53-58.

Allen E. Bergin, "Some Implications of Psychotherapy Research for Therapeutic Practice." Journal of Abnormal Psychology, 1966, 71:235-246.

L. M. Boyd, "Most Disappointed Men in the World." San Francisco Chronicle, March 15, 1969.

Wagner H. Bridger and Irwin J. Mandel, "A Comparison of GSR Fear Responses Produced by Threat and Electric Shock." Journal of Psychiatric Research, 1964, 


\section{Social Learning Theory}

James L. Bruning, "Direct and Vicarious Effects of a Shift in Magnitude of Reward on Performance," Journal of Personality and Social Psychology, 1965, 2:278282.

T. Budzynski, J. Stoyva, and C. Adler, "Feedback-Induced Muscle Relaxation: Application to Tension Headache." Journal of Behavior Therapy and Experimental Psy. chiatry, 1970, 1:205-211.

Donald T. Campbell, "Conformity in Psychology's Theories of Acquired Behavioral Dispositions." In Irwir A. Berg and Bernard M. Bass, eds., Conformity and Deviation. Harper, 1961.

Randall M. Chambers, "Effects of Intravenous Glucose Injections on Learning, General Activity, and Hunger Drive." Journal of Comparative and Physiological Psychology, 1956, 49:558-564.

Bishwa B. Chatterjee and Charles W. Eriksen, "Cognitive Factors in Heart Rate Conditioning." Journal of Experimental Psychology, 1962, 64:272-279.

Russell M. Church, "Emotional Reactions of Rats to the Pain of Others." Journal of Comparative and Physiological Psychology, 1959, 52:132-134.

Brian Coates and Willard W. Hartup, "Age and Verbalization in Observational Learning." Developmental Psychology, 1969, 1:556-562.

K. N. Condrell, "Vicarious Leaming of a Discrimination Learning Problem as a Function of Reinforcement and Set." Dissertation Abstracts, 1967, 28:1221.

Harold W. Coppock and Randall M. Chambers, "Reinforcement of Position Preference by Automatic Intravenous Injections of Glucose." Journal of Comparative and Physiological Psychology, 1954, 47:355-357.

Harold W. Coppock, C. P. Headlee, and W. R. Hood, "Negative Reinforcing Effects of Insulin Injections." American Psychologist, 1953, 8:337.

Philip A. Cowan, Jonas Langer, Judith Heavenrich, and Marjorie Nathanson, "Social Learning and Piaget's Cognitive Theory of Moral Development." Journal of Personality and Social Psychology, 1969, 11:261-274.

Kenneth D. Craig and Malcolm S. Weinstein, "Conditioning Vicarious Affective Arousal." Psychological Reports,
1965, 17:955-963.

Judith L. Crooks, "Observational Leaming of Fear in Monkeys." Unpublished manuscript, University of
Pennsylvania, 1967.

J. P. Das and P. C. Nanda, "Mediated Transfer of Attitudes." Journal of Abnormal and Social Psychology,

Michael E. Dawson, "Comparison of Classical Conditioning and Relational Learning." Unpublished MA thesis, University of Southern California, 1966

Michael E. Dawson and William W. Grings, "Comparison Journal of Experitioning and Relational Learning." 231.

Michael E. Dawson and James H. Satterfeld, "Can Human GSR Conditioning Occur without Relational Learning?" Proceedings of the American Psychological Association, 1969, 69-70.

E. Dekker and J. Groen, "Reproducible Psychogenic Attacks of Asthma: a Laboratory Study." Joumal of Psy-
chosomatic Research, 1956, 1:58-67.
E. Dekker, H. E. Pelser, and J. Groen, "Conditioning as a Cause of Asthmatic Attacks." Journal of Psychosomatic Research, 1957, 2:97-108.

Raymond Ditrichs, Seymore Simon, and Barry Greene, "Effect of Vicarious Scheduling on the Verbal Conditioning of Hostility in Children." Journal of Personality and Social Psychology, 1967, 6:71-78.

Donelson E. Dulany, "The Place of Hypotheses and Intentions: an Analysis of Verbal Control in Verbal Conditioning." In Charles W. Eriksen, ed., Behavior and-Awareness-A Symposium of Research and Inter. pretation. Duke University Press, 1962.

Donelson E. Dulany, "Awareness, Rules, and Propositional Control: a Confrontation with S-R Behavior Theory." In Theodore R. Dixon and David L. Horton, eds., Verbal Behavior and General Behavior Theory. Prentice-Hall, 1968.

Donelson E. Dulany and Daniel C. O'Connell, "Does Partial Reinforcement Dissociate Verbal Rules and the Behavior They Might be Presumed to Control?" Journal of Verbal Learning and Verbal Behavior, 1963, Joseph W. Eaton and Robert J. Weil, Culture and Mental
Disorders. Free Press, 1955.

Charles W. Eriksen and James L. Kuethe, "Avoidance Conditioning of Verbal Behavior Without Awareness: a Paradigm of Repression." Journal of Abnormal and Social Psychology, 1956, 53:203-209.

Charles B. Ferster, John I. Nurnberger, and Eugene B Levitt, The Control of Eating." Journal of Mathetics,
$1962,1: 87-109$.

Charles B. Ferster and B. F. Skinner, Schedules of Rein forcement. Appleton, 1957.

James P. Flanders, “A Review of Research on Imitative Behavior." Psychological Bulletin, 1968, 69:316337.

Cyril M. Franks. Behavior Therapy. McGraw-Hill, 1969.

Marcus J. Fuhrer and Paul E. Baer,. "Differential Classical Conditioning: Verbalization of Stimulus Contingencies." Science, 1965, 150:1479-1481.

Elliot N. Gale and Marsha B. Jacobson, "The Relationship between Social Comments as Unconditioned Stimuli and Fear Responding." Behaviour Research and Therapy, 1970, 8:301-307.

James H. Geer, "A Test of the Classical Conditioning Model of Emotion: the Use of Nonpainful Aversive Stimuli as Unconditioned Stimuli in a Conditioning Procedure." Journal of Personality and Social Psychology, 1968, 10:148-156.

Marvin S. Gerst, "Symbolic Coding Processes in Observational Learning." Journal of Personality and Social Psychology, 1971, 19:7-17.

Jacob L. Gewirtz and Karen,G. Stingle, "Learning of Generalized Imitation as the Basis for Identification." Psychological Review, 1968, 75:374-397.

E. L. Glynn, "Classroom Applications of Self-Determined Reinforcement." Joumal of Applied Behavior Analysis,

G. R. Goodlet and M. M. Goodlet, "Efficiency of SelfMonitored and Externally Imposed Schedules of Reinforcement in Controlling Disruptive Behavior." Unpublished manuscript, University of Guelph, 1969. 
William W. Grings and Russell A. Lockhart, "Effects of 'Anxiety-Lessening' Instructions and Differential Set Development on the Extinction of GSR," Journal of Experimental Psychology, 1963, 66:292-299.

Robert F. Grose, "A Comparison of Vocal and Subvocal Conditioning of the Galvanic Skin Response." Unpublished doctoral dissertation, Yale University, 1952.

Florence R. Harris, Montrose M. Wolf, and Donald M. Baer, "Effects of Adult Social Reinforcement on Child Behavior." Young Children, 1964, 20:8-17.

Mary B. Harris, "A Self-Directed Program for Weight Control: a Pilot Study." Journal of Abnormal Psychology, 1969, 74:263-270.

Albert H. Hastorf, "The 'Reinforcernent' of Individual Actions in a Group Situation." In Leonard Krasner and Leonard P. Ullmann, eds., Research in Behavior Modification. Holt, Rinehart \& Winston, 1965.

Ralph F. Hefferline and Brian Keenan, "AmplitudeInduction Gradient of a Small-Scale (Covert) Op. erant." Journal of the Experimental Analysis of Behavior, 1963, 6:307-315.

Ralph F. Hefferline, Brian Keenan, and Richard A. Harford, "Escape and Avoidance Conditioning in Human Subjects without Their Observation of the Response." Science, 1959, 130:1338-1339.

Raúl Hernández-Péon, Harold Scherrer, and Michel Jouvet, "Modification of Electric Activity in Cochlear. Nucleus during 'Attention' in Unanesthetized Cats." Science, 1956, 23:331-332.

W. A. Hillix and Melvin H. Marx, "Response Strengthening by Information and Effect on Human Learning." Journal of Experimental Psychology, 1960, 60:97-102.

G. Horn, "Electrical Activity of the Cerebral Cortex of the Unanesthetized Cat during Attentive Behavior." Brain, 1960, 83:57-76.

Charles C. Hughes, Marc-Abelard Tremblay, Robert $N$ Rapoport, and Alexander H. Leighton, Pcoplc of Cove' and Woodlot: Communitics from the Viewpoint of
Social Psychiatry. Basic Books, 1960 .

Chester A. Insko and William F. Oakes, "Awareness and the 'Conditioning' of Attitudes." Journal of Pcrsonality and Social Psychology, 1966, 4:487-496.

E. Roy John, Mechanisms of Memory. Academic, 1967. Joe Kamiya, "Conscious Control of Brain Waves." Psy.
chology Today, 1968, 1(11):57-61.

Frederick H. Kanfer and Albert R. Marston, "Determi. nants of Self-Reinforcement in Human Learning." Journal of Experimental Psychology, 1963, 66:245.
254.

Arnold Kaufman, Alan Baron, and Rosemarie E. Kopp, "Some Effects of Instructions on Human Operant Behavior." Psychonomic Monograph Supplements, 1966,
I:243-250.

Thomas D. Kennedy, "Verbal Conditioning Without Awareness: the Use of Programmed Reinforcement and Recurring Assessment of Awareness." Journal of Experimental Psychology, 1970, 84:484-494.

Thomas D. Kennedy, "Reinforcement Frequency, Task Characteristics, and Interval of Awareness Assessment as Factors in Verbal Conditioning Without Awareness." Journal of Experimental Psychology, 1971, 88:103-
Gregory A. Kimble, Hilgard and Marquis Conditioning and Learning. Appleton-Century-Crofts, 1961.

Monroe Lefkowitz, Robert Rogers Blake, and Jane S. Mouton, "Status Factors in Pedestrian Violation of Traffic Signals." Journal of Abnormal and Social Psy. chology, 1955, 51:704-705.

Robert M. Liebert, Richard D. Odom, Jae H. Hill, and R. L. Huff, "Effects of Age and Rule Familiarity on the Production of Modeled Language Constructions." Developmental Psychology, 1969, 1:108-112.

Richard H. Lindley and Kenneth E. Moyer, "Effects of Instructions on the Extinction of a Conditioned FingerWithdrawal Response." Journal of Experimental Psychology, 1961, 61:82-88.

Ronald R. Lippitt, Norman Polansky, and Sidney Rosen, "The Dynamics of Power." Human Relations, 1952, 5:37-64.

Armin Loeb, Aaron T. Beck, James C. Diggory, and Robert Tuthill, "Expectancy, Level of Aspiration, Performance, and Self-Evaluation in Depression." Proceedings of the 75th Annual Convention of the American Psychological Association, 1967, 2:193-194.

O. Ivar Lovaas, "A Behavior Therapy Approach to the Treatment of Childhood Schizophrenia." In J. P. Hill, ed., Minnesota Symposia on Child Psychology, rol. I. University of Minnesota Press, 1967.

Thomas C. Lovitt and Karen A. Curtis, "Academic Re. sponse Rate as a Function of Teacher- and SelfImposed Contingencies." Journal of Applied Behavior Analysis, 1969, 2:49-53.

Arthur A. Lumsdaine, ed., Student Response in ProErammed lnstruction. National Academy of SciencesNational Research Council, 1961.

John W: MeDilvid, "Effects of Ambiguity of Imititive Cues upon Learning by Observation." Journal of Social Psychology, 1964, 62: 165-174.

R. M. Mutire, I. M. Carlisle, and B. G. Young, "Sexual Deviations as Conditioned Behavior: a Hypothesis." Bchavior Research and Therapy, 1965, 2:185-190.

Michael J. Mc.Mains and Robert M. Liebert, "Influence of Discrepincies between Successively Modeled SelfReward Criteria on the Adoption of a Self-Imposed Standard." Journal of Personality and Social Psychology, 1968, 8:166-171.

Irvin J. Mandel and Wagner H. Bridger, "Interaction between Instructions and ISI in Conditioning and Extinction of the GSR." Journal of Experimental Psychology, 1967, 74:36-43.

Isaac M. Marks and Michael C. Gelder, "Transvestism and Fetishism: Clinical and Psychological Changes during Faradic Aversion." British Journal of Psychiatry, 1967, 113:711-729.

Gordon A. Marlatt, "Vicarious and Direct Reinforcement Control of Verbal Behavior in an Interview Setting." Unpublished doctoral dissertation, Indiana University,
1968 .

J. Marmor, "Psychoanalytic Therapy as an Educational Process: Common Denominators in the Therapeutic Approaches of Different Psychoanalytic 'Schools'." In Jules H. Masserman, ed., Science and Psychoanalysis. vol. 5, Psychoanalytic Education. Grune \& Stratton, 
Albert R. Marston, "Imitation, Self-Reinforcement, and Reinforcement of Another Person." Journal of Personality and Social Psychology, 1965a, 2:255-261.

Albert R. Marston, "Self Reinforcement: the Relevance of a Concept in Analogue Research in Psychotherapy." Psychotherapy: Theory, Research and Practice, 1965b, 2:1-5.

Donald N. Michael and Nathan Maccoby, "Factors Influencing the Effects of Student Participation on Verbal Learning from Films: Motivating versus Practice Effects, 'Feedback,' and Overt versus Covert Responding," In Arthur A. Lumsdaine, ed., Student Response in Programmed Instruction. National Academy of Sciences-National Research Council, 1961.

Neal E. Miller, "Studies of Fear as an Acquirable Drive: I. Fear as Motivation and Fear-Reduction as Reinforcement in the Learning of New Responses." Journal of Experimental Psychology, 1948, 38:89-101.

Neal E. Miller, "Leamable Drives and Rewards." In S. S. Stevens, ed., Handbook of Experimental Psychology. Wiley, 1951.

Neal E. Miller, "Learning of Visceral and Glandular Responses." Science, 1969, 163:434-445.

Neal E. Miller, Leo V. Di Cara, Henry Solomon, Jay M Weiss, and Barry Dworkin, "Learned Modifications of Autonomic Functions: a Review and Some New Data." Circulation Research, Supplement I, 26 \& 27, 1970; 3-11.

Neal E. Miller and John Dollard, Social Learning and Imitation. Yale University Press, 1941.

Walter Mischel, Personality and Assessment. Wiley, 1968.

Walter Mischel and Robert M. Liebert, "Effects of Discrepancies between Observed and Imposed Reward Criteria on Their Acquisition and Transmission." Journal of Personality and Social Psychology, 1966, 3: 45-53.

Don Moser, "Screams, Slaps, and Love." Life, May 7, $1965,90 \mathrm{~A}-101$.

Kenneth E. Moyer and Richard H. Lindley, "Supplementary Report: Effects of Instructions on Extinction and Recovery of a Conditioned Avoidance Response." Journal of Experimental Psychology, 1962, 64: 95-96.

Edward James Murray, "A Content-Analysis Method for Studying Psychotherapy." Psychological Monographs, 1956, 70 (13), whole no. 420

Joseph M. Notterman, William N. Schoenfeld, and Philip J. Bersh, "A Comparison of Three Extinction Procedures Following Heart Rate Conditioning." Journal of Abnormal and Social Psychology, 1952, 47:674-677.

Edwin P. Parker, "Information Utilities and Mass Communication." In Harold Sackman and Norman Nie, eds., Information Utility and Social Choice. AFIPS Press, 1970.

Catherine R. Porro, "Effects of the Observation of a Model's Affective Responses to Her Own Transgression on Resistance to Temptation in Children." Dissertation Abstracts, 1968, 28:3064

Leo Postman and Julius Sassenrath, "The Automatic Action of Verbal Rewards and Punishments." Journal of General Psychology, 1961, 65:109-136.

Stanley Rachman, "Sexual Fetishism: an Experimental Analogue." Psychological Record, 1966, 16:293-296.
Harold L. Rausch, "Interaction Sequences." Journal of Personality and Social Psychology, 1965, 2:487-499.

Gregory Razran, "The Observable Unconscious and the Inferable Conscious in Current Soviet Psychophysiology." Psychological Review, 1961, 68:81-147.

William J. Redd and Jay S. Bimbrauer, "Adults as Discriminative Stimuli for Different Reinforcement Contingencies with Retarded Children." Journal of Experimental Child Psychology, 1969, 7:440-447.

David Riesman, The Lonely Crowd. Yale University Press, 1950.

Mary A. Rosekrans and Willard W. Hartup, "Imitative Influences of Consistent and Inconsistent Response Consequences to a Model on Aggressive Behavior in Children." Journal of Personality and Social Psychology, 1967, 7:429-434.

Gerald Rosenbaum, "Stimulus Generalization as a Function of Level of Experimentally Induced Anxiety." Journal of Experimental Psychology, 1953, 45:35-43.

Gerald Rosenbaum, "Stimulus Generalization as a Function of Clinical Anxiety," Journal of Abnormal and Social Psychology, 1956, 53:281-285.

Milton E. Rosenbaum, "The Effect of Stimulus and Background Factors on the Volunteering Response." Journal of Abnormal and Social Psychology, 1956, 53:118-121.

Milton E. Fosenbaum and James L. Bruning, "Direct and Vicarious effects of Variations in Percentage of Reinforcement on Performance." Child Development, 1966 , 37:959-966.

Milton E. Rosenbaum and Oliver J. Hewitt, "The Effect of Electric Shock on Learning by Performers and Observers." Psychonomic Science, 1966, 5:81-82.

Duvid Rosenhan, F. Frederick, and Anne Burrowes, "Preaching and Practicing: Effects of Channel Discrepancy on Norm Internalization." Child Develop. ment, 1968, 39:291-301.

Ted L. Rusenthal and Joan S. Whitebook, "Incentives versus Instructions in Transmitting Grammatical Parameters with Experimenter as Model." Behaviour Re. search and Therapy, 1970, 8:189-196.

Ted L. Rosenthal and Barry J. Zimmerman, "Modeling by Exemplification and Instruction in Training Conservation." Unpublished manuscript, University of Arizona, 1970

Ted L. Rosenthal, Barry J. Zimmerman, and Kathleeı. Durning. "Observationally-Induced Changes in Chil. dren's Interrogative Classes." Journal of Personality and Social Psychology, 1970, 16:681-688.

Jack Sandler and John Quagliano, "Punishment is a Signal Avoidance Situation." Paper read at Southeastern Psychological Association meeting, Gatlinburg, Tenn., 1964.

Robert M. Sasmor, "Operant Conditioning of a SmallScale Muscle Response." Joumal of the Experimental Analysis of Behavior, 1966, 9:69-85.

M. Sidman, "Avoidance Behavior." In Werner K. Honig, ed., Operant Behavior. Appleton-Century-Crofts, 1966.

B. F. Skinner, Science and Human Behavior. Macmillan, 1953.

Henry Slucki, Gyorgi Adam, and Robert W. Porter, "Operant Discrimination of an Interoceptive Stimulus in Rhesus Monkeys." Joumal of the Experimental Analysis of Behavior, 1965, 8:405-414. 


\section{Albert Bandura}

Charles D. Spielberger and L. Douglas De Nike, "Descriptive Behaviorism versus Cognitive Theory in Verbal Operant Conditioning." Psychological Review, 1966, 73:306-326.

Arthur W. Staats and Carolyn K. Staats, "Attitudes Established by Classical Conditioning." Joumal of $A b$ normal and Social Psychology, 1958, 57:37-40.

Carolyn K. Staats and Arthur W. Staats, "Meaning Established by Classical Conditioning." Joumal of Experimental Psychology, 1957, 54:74-80.

Lewis J. Stone and Jack E. Hokanson, "Arousal Reduction via Self-Punitive Behavior." Journal of Personality and Social Psychology, 1969, 12:72-79.

Richard B. Stuart, "Behavioral Control of Overeating" Behaviour Research and Therapy, 1967, 5:357-365.

J. S. Stumphauzer, "Increased Delay of Gratification in Young Prison Inmates through Imitation of HighDelay Peer-Models." Unpublished doctoral dissertation, Florida State University, 1969.

Edmund V. Sullivan. "The Acquisition of Conservation of Substance through Film-Mediated Models." In D. W. Brison and Edmund V. Sullivan, eds., Recent Research on the Acquisition of Conservation of Substance, Education Monograph. Toronto: Ontario Institute for Studies in Education, 1967.

Charles B. Truax, "Reinforcement and Nonreinforcement in Rogerian Psychotherapy." Joumal of Abnormal Psychology, 1966, 71:1-9.

Richard H. Walters, Marion Leat, and Louis Mezei, "Inhibition and Disinhibition of Responses through Empathetic Leaming." Canadian Joumal of Psychol-
ogy, 1963, 17:235-243.
Richard H. Walters and Ross D. Parke, "Influence of Response Consequences to a Social Model on Resistance to Deviation." Journal of Experimental Chill Psychology, 1964, 1:269-280.

Richard H. Walters, Ross D. Parke, and Valerie A Cane, "Timing of Punishment and the Observation of Consequences to Others as Determinants of Response Inhibition." Journal of Experimental Child Psychology, $1965,2: 10-30$.

D. Walton and M. D. Mather, "The Application of Learning Principles to the Treatment of ObsessiveCompulsive States in the Acute and Chronic Phases of Illness." Behaviour Research and Therapy, 1963, 1:163-174.

John B. Watson and Rosalie Rayner, "Conditioned Emotional Reactions." Journal of Experimental Psychology, 1920, 3:1-14.

Harold Weiner, "Real and Imagined Cost Effects upon Human Fixed-Interval Responding." Psychological Reports, 1965, 17:659-662.

Alfred E. Weisz and Robert L. Taylor, "American Presidential Assassinations." In David N. Daniels, Marshall F. Gilula, and Frank M. Ochberg, eds., Violence and the Struggle for Existence." Little, Brown, 1970

Delos D. Wickens, Charles K. Allen, and Frances A. Hill, "Effects of Instruction and UCS Strength on Extinction of the Conditioned GSR." Joumal of Experimental Psychology, 1963, 66:235-240.

William C. Wilson, "Imitation and Learning of Incidental Cues by Preschool Children." Child Development,
1958, 29:393-397. 